\title{
DUSP12 regulates the tumorigenesis and prognosis of hepatocellular carcinoma
}

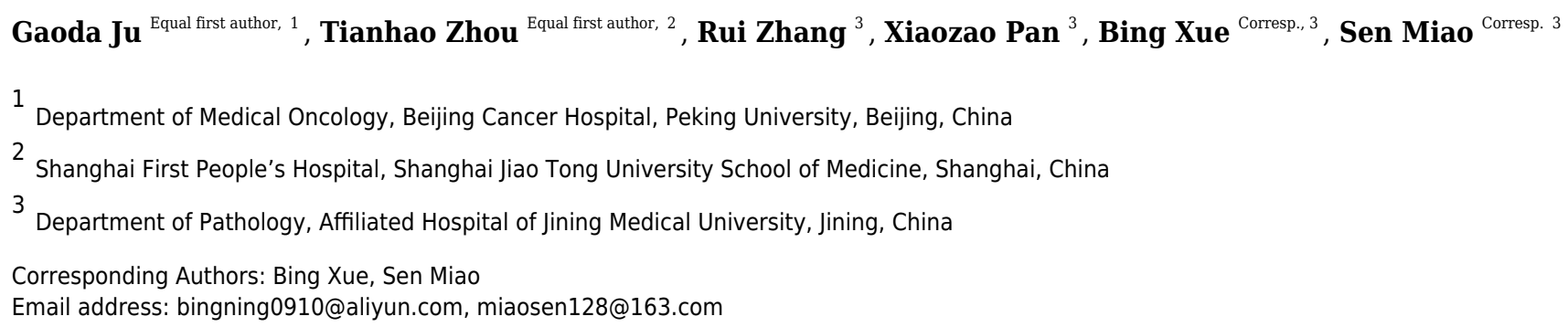

Background: Dual specificity protein phosphatase (DUSP)12 is an atypical member of the protein tyrosine phosphatase family, which are overexpressed in multiple types of malignant tumors. This protein family protect cells from apoptosis and promotes the proliferation and motility of cells. However, the pathological role of DUSP12 in hepatocellular carcinoma (HCC) is incompletely understood. Methods: We analyzed mRNA expression of DUSP12 between HCC and normal liver tissues using multiple online databases, and explored the status of DUSP12 mutants using the cBioPortal database. The correlation between DUSP12 expression and tumor-infiltrating immune cells was demonstrated using the Tumor Immune Estimation Resource database, and Tumor and Immune System Interaction Database. Loss of function assay was utilized to evaluate the role of DUSP12 in HCC progression.Results: DUSP12 had higher expression along with mRNA amplification in HCC tissues compared with those in normal liver tissues, which suggested that higher DUSP12 expression predicted shorter overall survival. Analyses of functional enrichment of differentially expressed genes suggested that DUSP12 regulated HCC tumorigenesis, and that knockdown of DUSP12 expression by short hairpin (sh)RNA decreased the proliferation and migration of HCC cells. Besides, DUSP12 expression was positively associated with the infiltration of cluster of differentiation (CD) $4+T$ cells (especially CD4+ regulatory T cells), macrophages, neutrophils and dendritic cells. DUSP12 expression was positively associated with immune-checkpoint moieties, and was downregulated in a C3 immune-subgroup of HCC (which had the longest survival). Conclusion: These data suggest that DUSP12 may have a critical role in the tumorigenesis, infiltration of immune cells, and prognosis of HCC. 
1 DUSP12 regulates the tumorigenesis and prognosis of 2 hepatocellular carcinoma

3 Gaoda Jü ${ }^{1 \#}$, Tianhao Zhou ${ }^{2 \#}$, Rui Zhang ${ }^{3}$, Xiaozao Pan ${ }^{3}$, Bing Xue ${ }^{3}$, Sen $\mathrm{Miao}^{3}$ 4

$5 \quad{ }^{1}$ Department of Medical Oncology, Beijing Cancer Hospital, Peking University, Beijing, 102206, 6 China.

7 'Shanghai First People's Hospital, Shanghai Jiao Tong University School of Medicine, Shanghai, 8 200080, China

9 32Department of Pathology, Affiliated Hospital of Jining Medical University, Jining, 272000, 10 China 11

\#Contributed equally

14 Corresponding Authors:

15 Sen Miao $^{3}$

16 Jining, 272000, P.R. China.

17 Email address: miaosen128@163.com

18

19

20

Bing Xue ${ }^{3}$, Jining, 272000, P.R. China.

21 Email address: bingning0910@aliyun.com

22

23

24

25

26

27

28

29

30

31

32

33

34

35

36

37 


\section{Abstract}

Background: Dual specificity protein phosphatase (DUSP) 12 is an atypical member of the protein tyrosine phosphatase family, which are overexpressed in multiple types of malignant tumors. This protein family protect cells from apoptosis and promotes the proliferation and motility of cells. However, the pathological role of DUSP12 in hepatocellular carcinoma (HCC) is incompletely understood.

Methods: We analyzed mRNA expression of DUSP12 between HCC and normal liver tissues using multiple online databases, and explored the status of DUSP12 mutants using the cBioPortal database. The correlation between DUSP12 expression and tumor-infiltrating immune cells was demonstrated using the Tumor Immune Estimation Resource database, and Tumor and Immune System Interaction Database. Loss of function assay was utilized to evaluate the role of DUSP12 in HCC progression.

Results: DUSP12 had higher expression along with mRNA amplification in HCC tissues compared with those in normal liver tissues, which suggested that higher DUSP12 expression predicted shorter overall survival. Analyses of functional enrichment of differentially expressed genes suggested that DUSP 12 regulated HCC tumorigenesis, and that knockdown of DUSP12 expression by short hairpin (sh)RNA decreased the proliferation and migration of HCC cells. Besides, DUSP12 expression was positively associated with the infiltration of cluster of differentiation (CD)4+ T cells (especially CD4+ regulatory $\mathrm{T}$ cells), macrophages, neutrophils and dendritic cells. DUSP12 expression was positively associated with immune-checkpoint moieties, and was downregulated in a $\mathrm{C} 3$ immune-subgroup of $\mathrm{HCC}$ (which had the longest survival).

Conclusion: These data suggest that DUSP12 may have a critical role in the tumorigenesis, infiltration of immune cells, and prognosis of HCC.

Keywords: hepatocellular carcinoma, DUSP12, mutation, tumorigenesis, prognosis 
84

85

86

87

88

89

90

91

92

93

94

95

96

97

98

99

100

101

102

103

104

105

106

107

108

109

110

111

112

113

114

115

116

117

118

119

120

121

122

123

\section{Introduction}

Hepatocellular carcinoma (HCC) is the most common malignant tumor of the liver (Ferlay et al. 2015). HCC is the third most prevalent cause of cancer-specific death worldwide (Bray et al. 2018). Due to rapid progression, HCC is usually discovered and diagnosed at an advanced stage, which leads to the loss of feasibility of treatments (Chen et al. 2016). Systemic chemotherapy for HCC is limited because HCC lacks sufficient targets for drugs, and HCC evolves resistance to classic anti-tumor agents (Fitzmorris et al. 2015; Lohitesh et al. 2018). The median duration of survival of patients with advanced HCC is $\sim 1$ year (Llovet et al. 2018; Zhu et al. 2015).

Dual specificity protein phosphatase $(D U S P) 12$ is an atypical member of the protein tyrosine phosphatase (PTP) family. DUSP 12 regulates the proliferation, apoptosis, and migration of cells by dephosphorylating tyrosine and serine/threonine residues (Guan et al. 1991; Patterson et al. 2009). It has been reported that DUSP12 is overexpressed in intracranial ependymoma, retinoblastomas, and neuroblastomas (Gratias et al. 2005; Hirai et al. 1999; Mendrzyk et al. 2006). Some research teams have found that DUSP12 overexpression protects HeLa cells from apoptosis and promotes the proliferation and motility of HEK293 cells (Cain et al. 2011; Sharda et al. 2009). Several studies have reported that DUSP12 overexpression in macrophages could reduce expression of proinflammatory cytokines such as tumor necrosis factor- $\alpha$, interleukin (IL)-1 and IL-6, and increase IL-10 expression. DUSP12-expressed hepatocytes are less inflamed and cause less hepatic steatosis than DUSP12-deleted hepatocytes (Cho et al. 2017; Huang et al. 2019). However, the correlation between DUSP 12 expression and HCC tumorigenesis and DUSP 12 function in cells is not known.

We explored the expression, mutation, and pathological role of DUSP 12 in HCC by integrated analyses of various data sources using online tools. The latter were applied to analyze the correlation of target genes with different cancer types, but especially HCC. In this way, we hoped to help researchers investigate the molecular targets of tumorigenesis.

\section{Materials \& Methods}

\subsection{Public databases}

\subsubsection{Ualcan}

Ualcan (http://ualcan.path.uab.edu/) is an interactive Internet resource for analyzing cancer OMICS data. Ualcan was used to analyze transcription expression, prognosis, and the methylation of genes in The Cancer Genome Atlas (TCGA) datasets (Chandrashekar et al. 2017). The TCGA-Liver Hepatocellular Carcinoma (LIHC) dataset was employed in our research.

\subsubsection{Gene Expression Profiling Interactive Analysis (GEPIA)}

The GEPIA database (http://gepia.cancer-pku.cn/) was used to plot overall survival (OS) and disease-free survival (DFS) curves. Group cutoff was based on the median of gene expression and prognostic status of patients in the TCGA-LIHC dataset (Tang et al. 2017).

\subsubsection{Kaplan-Meier Plotter (liver cancer)}


124 Kaplan-Meier Plotter (http://kmplot.com/analysis/index.php/) was employed for OS (including 125364 patients), DFS (including 316 patients), progression-free survival (PFS) (including 370 126 patients) and disease-specific survival (DSS) (including 262 patients) analysis using data from 127 RNA-sequencing of a liver-cancer dataset (Menyhárt et al. 2018). We separated high and low 128 expression based on the best cutoff expression value of $D U S P 12$ that all possible cutoff values 129 between lower and upper quartiles were computed, and the best performing threshold was used 130 as a cutoff.

131

2.1.4. Human Protein Atlas (HPA)

The HPA database (www.proteinatlas.org/) was used to validate gene expression in liver-cancer tissues and normal liver tissues at the protein level (Uhlén et al. 2015; Uhlen et al. 2017).

135

136

137

2.1.5. Cancer Cell Line Encyclopedia

138

139

140

141

142

143 The Cancer Cell Line Encyclopedia database (www.broadinstitute.org/ccle/) was employed to analyze gene expression in HCC cells (Ghandi et al. 2019). RNA-expression data of liver-cancer cell lines were downloaded from this website for our research.

\subsubsection{HCCDB}

Hepatocellular Cancer Database (HCCDB) (http://lifeome.net/database/hccdb/home.html/) is an integrative molecular database of $\mathrm{HCC}$ with 15 datasets. Co-expressed genes were computed and displayed in HCC according the guidelines on the HCCDB website (Lian et al. 2018). The normalized expression data of ICGC-LIRI-JP and GSE14520 were downloaded from HCCDB.

\subsection{7. cBioPortal}

The cBioPortal database (http://cbioportal.org/) is an online tool for analyzing the mutation characteristics of genes in a Liver Hepatocellular Carcinoma (TCGA, Firehose Legacy) dataset (Cerami et al. 2012; Gao et al. 2013). A total of 392 differentially expressed genes (DEGs) were identified from a DUSP12-altered group and DUSP12-nonaltered group of patients.

152

153

\subsubsection{Tumor Immune Estimation Resource (TIMER)}

154

The correlation of copy number variation (CNV) of genes with the abundance of tumor-

155 infiltrating immune cells (TIICs) was displayed by an online tool in the TIMER database (Li et al. 2016; Li et al. 2017). In this way, we analyzed the correlation of gene expression with TICC abundance and expression of immune-checkpoint moieties in the TCGA-LIHC dataset (https://cistrome.shinyapps.io/timer/), the list of correlations was filtered for interactions with $P$ $<0.05$ and correlation coefficient $>0.2$.

160 different immune subtypes of HCC (Ru et al. 2019). 
164

165

166

167

168

169

170

171

172

173

174

175

176

177

178

179

180

181

182

183

184

185

186

187

188

189

190

191

192

193

194

195

196

197

198

199

200

201

202

\subsubsection{CIBERSORT}

A total of 369 tumor samples extracted from the Genomic Data Commons (GDC)-TCGA-LIHC dataset were downloaded from UCSC.XENA (http://xena.ucsc.edu/). The CIBERSORT method was used within the R package (www.r-project.org/) (Goldman et al. 2020; Newman et al. 2019). After removing samples with $P \geq 0.05$ in the result of CIBERSOT analysis, the remaining 261 samples were divided into high and low expression groups based on median expression of DUSP12. Bar graphs of the TIIC ratio between high and low expression groups were plotted with Prism 7 (GraphPad, San Diego, CA, USA).

\subsubsection{Metascape}

Metascape (http://metascape.org/) is a resource to aid the annotation and analyses of genes, which helps biologists make sense of one or multiple gene lists. Metascape was applied for analyses of protein-protein interaction (PPI) networks. Analyses of functional enrichment and enrichment of pathways were done using Gene Ontology (GO), Kyoto Encyclopedia of Genes and Genomes (KEGG) and DisGeNET databases (Zhou et al. 2019).

\subsubsection{DepMap Portal database}

DepMap Portal (https://depmap.org/portal/) database is utilized to evaluate the probabilities of dependency of DUSP12 in HCC cell lines with CERES score based on data from CRISPR (DepMap 21Q2 Public + Score, CERES) cohort (Broad 2021).

\subsection{Cell lines and culture conditions}

The human liver-cancer cell line Huh7 was acquired from American Type Culture Collection (Manassas, VA, USA) and cultivated in Dulbecco's modified Eagle's medium (DMEM; Gibco, Grand Island, NY, USA) with 10\% fetal bovine serum (Gibco) and 1\% penicillin-streptomycin (Gibco) at $37^{\circ} \mathrm{C}$ in an atmosphere of $5 \% \mathrm{CO}_{2}$.

\subsection{Western blotting}

Cell proteins were extracted by denaturing buffer and then quantified by a bicinchoninic acid protein assay (Thermo Scientific, Waltham, MA, USA). Protein lysates from the HCC cell line were separated by sodium dodecyl sulfate-polyacrylamide gel electrophoresis, transferred to nitrocellulose membranes (Millipore, Bedford, MA, USA), blocked, and then detected by primary antibody DUSP12 (1:2000 dilution; catalog number: ab237008; Abcam, Cambridge, UK) and horseradish peroxidase-conjugated secondary antibody (Sigma-Aldrich, Saint Louis, MO, USA). These actions were followed by exposure to enhanced chemiluminescence. The housekeep gene $\beta$-tubulin (1:500; ab6046; Abcam) was used as a loading control.

\subsection{Plasmids and lentivirus production}


203 Annealing and connection of short hairpin (sh)RNA were undertaken followed by construction 204 into the modified plasmid pLKO.1. Well-constructed vectors were transinfected into HEK293T 205 cells by lentivirus packaging plasmids psPAX and pMD2.0G. The shRNA sequences and

206 DUSP12 primer sequence (forward and reverse, respectively) were:

207 CCGGGTTGAGTGGCAACTGAAATTATCTCGAGATAATTTCAGTTGCCACTCAAGTTT 208 TTG, and

209 AATTCAAAAAGTTGAGTGGCAACTGAAATTATCTCGAGATAATTTCAGTTGCCACTC 210 AAG for $\operatorname{sh}$ DUSP12-1;

211 CCGGGTGGATACCTCTAGTGCAATTCTCGAGAATTGCACTAGAGGTATCCACTTTTT

$212 \mathrm{G}$, and

213 AATTCAAAAAGTGGATACCTCTAGTGCAATTCTCGAGAATTGCACTAGAGGTATCCA

214 C for shDUSP12-2.

215

216

\subsection{Cell-growth assay}

217 Lentivirus-infected stable cells were seeded into 96-well plates and cultured in DMEM 218 containing $10 \%$ fetal bovine serum (2000 cells per well, five parallel wells). Then, cells were 219 collected at different timepoints. The cell number in each well was counted by Cell Counting Kit 220 221 8 (CCK8). Absorbance at $450 \mathrm{~nm}$ was measured to determine of the number of viable cells.

224

225

226

227

228

229

230

231

232

233

234

235

236

237

238

239

240

241

242

\subsection{TranswellTM assay}

Lentivirus-infected stable cells were seeded in the upper chamber of a Transwell chamber (24well ( 8 - $\mu \mathrm{m}$ pore; Corning, Corning, NY, USA) in $200 \mu \mathrm{L}$ of serum-free DMEM $\left(1 \times 10^{5}\right.$ cells per well, five parallel wells). Then, $800 \mu \mathrm{L}$ of DMEM containing $10 \%$ fetal bovine serum was added to the lower chamber and incubation allowed for $36 \mathrm{~h}$ at $37^{\circ} \mathrm{C}$. After removing the cells at the upper surface of the membrane, cells were passed through a filter and fixed with $4 \%$

paraformaldehyde, stained with $0.1 \%$ Crystal Violet solution and photographed using an inverted fluorescence microscope.

\section{Results}

\subsection{Pattern of DUSP12 transcriptional expression using Ualcan and HCCDB databases} Analyses of the TCGA-LIHC dataset in the Ualcan database and analyses of ICGC-LIRI-JP and GSE14520 cohorts revealed that transcriptional expression of DUSP12 was higher in LIHC tissues compared with that in normal liver tissues (Figure 1A, Figure S1). Analyses of clinical subgroups demonstrated that DUSP12 expression was higher in an Asian, tumor-nodemetastasis (TNM) stage-III, grade-3, P53-mutant group than that in a Caucasian, TNM stage-I/II, grade-1/2, P53-nonmutant group. The non-significant change in DUSP12 expression between the stage-IV/grade-4/N1 group compared with that in other groups may have been caused by the number of samples in the stage-IV/grade-4/N1 group being significantly less compared with that in other groups. The top positively and negatively correlated genes in TCGA dataset for DUSP12 were also downloaded from UALCAN database (Figure S1 and S2). We suspected that DUSP12 
243

244

245

246

247

248

249

250

251

252

253

254

255

256

257

258

259

260

261

262

263

264

265

266

267

268

269

270

271

272

273

274

275

276

277

278

279

280

281

282

283

could be a pathological and prognostic marker of LIHC (Figure 1B-F). Integrative analyses of HCCDB revealed that mRNA expression of DUSP12 was higher in liver-cancer tissue compared with that in normal liver tissue in 11 cohorts (Figure 2A). Analyses of functional enrichment of genes co-expressed with DUSP12 in liver-cancer tissues using Metascape showed that these genes were engaged mainly in "histone methylation", "cullin RING ubiquitin ligase complexes", "nuclear specks" and "ubiquitin-like protein transferase activity" (Figure 2B-E).

\subsection{Validation of $D U S P 12$ expression in tissues at the protein level and liver-cancer lines}

DUSP12 expression was higher in liver-cancer tissues than that in normal liver tissues at the protein level, and this observation was validated by results from the HPA database (Antibody: HPA008840; cancer-patient ID: 2399; normal-patient ID: 3222) (Figure 3A, B) and HUH1 had the highest transcriptional expression of DUSP12 in liver-cancer cell lines (Figure 3C).

\subsection{Survival analyses of liver-cancer patients with different DUSP12 expression}

LIHC patients with higher expression of DUSP12 had shorter OS and DFS in the TCGA-LIHC dataset (Figure 4A, B). Next, we validated the result by survival analyses of liver-cancer patients in the Kaplan-Meier Plotter database. We showed that patients with higher expression of DUSP 12 had shorter OS, DFS, PFS and DSS than that of patients with lower expression of DUSP12 (Figure 4C-F).

\subsection{Analyses of DUSP12 expression using the cBioPortal database}

An online tool in the cBioPortal database was utilized to analyze the mutant status of DUSP12 in the Liver Hepatocellular Carcinoma (TCGA, Firehose Legacy) dataset. The mutant frequency of DUSP12 in HCC was 33.0\% (Figure 5A), which was composed mainly of amplification and high expression of mRNA (Figure 5B). mRNA expression of DUSP12 in HCC with amplification was higher than that in those without alteration (Figure 5C). HCC patients with altered DUSP12 had shorter OS than HCC patients with nonaltered DUSP12 (Figure 5D). CNV analyses revealed that mRNA expression of DUSP12 was higher in HCC patients with DUSP12-amplification and DUSP12-gain patients than in those with DUSP12-shallow deletion and DUSP12-diploid (Figure 6A). In general, mRNA expression of DUSP12 was correlated negatively with methylation of the promoter region of DUSP 12 in 359 HCC samples from the TCGA-LIHC (Firehose Legacy) dataset (Figure 6B). DUSP12-altered patients had a higher serum level of alpha fetoprotein (AFP) at procurement (Figure 6C), fraction of genome altered (Figure 6D) and worse histology grade in neoplasms (Figure 6E). In addition, we screened 392 DEGs between DUSP12-altered patients and DUSP12-nonaltered patients with false discovery rate $<0.05$ and $\mid \log ($ ratio $) \mid>1$ (Figure 7A). Analyses of functional enrichment and disease-related enrichment of these 392 DEGs revealed that these genes mainly took part in: "M61392: CHIANG LIVER CANCER SUBCLASS PROLIFERATION DN"; "M16496: CHIANG LIVER CANCER SUBCLASS CTNNB1 UP"; "M3268: CHIANG LIVER CANCER SUBCLASS PROLIFERATION UP” (Figure 7B, C). Minimal Common Oncology Data Elements (MCODE) analyses revealed clustering of seven MCODEs (Figure 7D). MCODE 1 mainly included proteins that took part in 
284 the cell cycle (e.g., cluster of differentiation (CD)K1, CDC20, PLK1), cell division or mitosis 285 (e.g., AURKB, BIRC5, KIF2C, CENPA, CENPF). MCODE 2 mainly included cytochrome P450 286 (CYP) monooxygenase proteins that took part in various types of metabolism. MCODE 3 mainly 287 included UDP-glucuronosyltransferase (UDPGT) proteins. MCODE 4 included GCK, OTC, 288 SDS, POLE2 and ATP6V1B1. MCODE 5 included SULT4A1, SULT1B1, HS6ST2, and 289 GAL3ST1. MCODE 6 mainly included C-C motif chemokine proteins. MCODE 7 included 290 FMO3, ACSL6 and HSD11B1. MCODE 1 and MCODE 2 may play a critical part in the

291

292

293

294

295

296

297

298

299

300

301

302

303

304

305

306

307

308

309

310

311

312

313

314

315

316

317

318

319

320

321

322

323 proliferation and biological activity of HCC cells. MCODE 6 may have a correlation with the infiltrations of immune cells in HCC samples.

\subsection{Analyses of DUSP12 expression using the TIMER database}

We explored the correlation of DUSP12 expression with TIICs by TIMER database. DUSP12 expression was moderately (partial correlation $>0.2$ ) positively correlated with the abundance of infiltrating B cells, CD4+ T cells, macrophages, neutrophils, and dendritic cells (Figure 8A).

Then, we explored the correlation between DUSP12 and immune cells with other immuneinfiltration analyzing methods (xCELL, EPIC, CIBERSORT). The result suggested that DUSP12 expression was moderately (partial correlation $>0.2$ ) positively correlated with the abundance of infiltrating B cells and CD4+ T cells regardless of the method employed (Table 1). DUSP12 expression had a moderately positive correlation with the immune-checkpoint moieties HAVCR2, TIGIT, CTLA4 and PD-1 (Figure 8B). The infiltration level of CD8+ T cells, macrophages, neutrophils, and dendritic cells was significantly different in DUSP12 with different CNV (Figure 8C). Furthermore, we explored mRNA expression of DUSP12 in patients with different immune-subgroup liver cancer using the TISIDB. We revealed that the $\mathrm{C} 1$ (wound healing) subgroup had the highest DUSP12 expression, whereas the C3 (inflammatory) and C6 (TGF- $\beta$ dominant) subgroups had lower expression of DUSP12 (Figure 8D). Furthermore, groups with high expression of DUSP12 had a higher ratio of T-regulatory cells $\left(\mathrm{T}_{\text {regs }}\right)$ and activated natural-killer cells compared with those with low expression of DUSP12 (Figure 9).

\subsection{Knockdown of DUSP12 expression decreases the proliferation and migration of Huh-7 cells}

We evaluated the probabilities of dependency of DUSP 12 in $22 \mathrm{HCC}$ cell line types with data from CRISPR (DepMap 21Q2 Public + Score, CERES) cohort. The CERES scores of cell lines ranged from -0.04 to -0.47 while mean value was equal to -0.21 (Figure $S 2$ ). In general, a lower score meant that a gene is more likely to be essential in a given cell line and a score $<0$ meant that down-regulation of a gene may inhibit the proliferation of a given cell line. Human livercancer cells (Huh-7) were transfected with a specific shRNA for DUSP12 (shDUSP12) and a nonspecific shRNA (NC) (Figure 10A). CCK8 and Transwell assays were utilized to evaluate the ability of cells to proliferate and migrate. Knockdown of DUSP12 expression led to the reduced proliferation and motility of Huh7 cells (Figure 10B, C). 
324

325

326

327

328

329

330

331

332

333

334

335

336

337

338

339

340

341

342

343

344

345

346

347

348

349

350

351

352

353

354

355

356

357

358

359

360

361

362

363

\section{Discussion}

We propose that expression of DUSP12, a member of the PTP family, was different in HCC tissues and normal liver tissues in multiple datasets. In addition, the clinical features of HCC patients had a strong relationship with DUSP12 expression, including ethnicity, TNM stage, histology grade, and P53-mutant status. Survival analyses using the Kaplan-Meier method demonstrated that HCC patients with higher expression of DUSP12 had shorter survival than those with lower expression of DUSP12.

A PPI network containing DUSP 12 and 20 genes in liver-cancer samples in HCCDB was constructed. These genes, including ubiquitin-conjugating enzyme E2T (UBE2T), ILF2, SETDB1, CCT3, and UFC1, were engaged mainly in histone methylation, cullin RING ubiquitin ligase complexes, nuclear specks, and ubiquitin-like protein transferase activity. UBE2T has been demonstrated to promote the growth of $\mathrm{HCC}$ cells by regulating ubiquitination of P53, transition of the G2/M phase of the cell cycle, and the protein kinase B signaling pathway (Liu et al. 2019a; Liu et al. 2017; Wei et al. 2019). IL-F2 is a transcription factor which regulates the growth of HCC cells by controlling mRNA expression of apoptosis-related proteins (Cheng et al. 2016). Setdb1 is a histone methyltransferase that also regulates the growth of HCC cells by P53 methylation (Fei et al. 2015). CCT3 shows high expression in liver cancer, and leads to short survival (Liu et al. 2019b). CCT3 triggers expression of YAP and TFCP2 to regulate HCC tumorigenesis (Liu et al. 2019b). Hence, DUSP12 may have a critical role in the processes mentioned above by interacting with proteins in this network.

The mutant status of DUSP12 in HCC patients was determined by utilizing an online tool in the cBioPortal database. We discovered that nearly one-third of HCC patients suffered a DUSP 12 mutation. Most of them experienced amplification and higher mRNA expression of DUSP 12. HCC patients with a DUSP12 mutation had shorter survival, higher serum level of AFP, and worse histology grade than those of patients with wild-type DUSP12. Taken together, these findings suggest the probability of an intimate correlation between DUSP 12 mutation and the pathology and prognosis of DUSP12 in HCC.

We also identified 392 DEGs between HCC patients with altered DUSP12 and HCC patients with nonaltered DUSP 12 . These DEGs mainly regulated the tumorigenesis and proliferation of HCC cells. MCODE analyses revealed clustering of seven MCODEs. Among them, MCODE 1 mainly comprised the mutations of CDK1, KIF2C, KIF18A, CENPA, and PLK1, which take part in the tumorigenesis and progression of liver cancer (Jung et al. 2019; Komatsu et al. 2009; Li et al. 2020; Li et al. 2011; Long et al. 2018; Luo et al. 2018; Wu et al. 2018; Zhang et al. 2015). MCODE 2 was composed mainly of members belonging to the CYP enzyme superfamily, which has a critical role in drug metabolism or chemical metabolism in the liver (Agundez 2004). Agundez and colleagues found that the activity of CYP enzymes was closely associated with the risk of liver cancer (Agundez 2004). MCODE 3 mainly included UDPGT proteins that take part in conjugation and subsequent elimination of potentially toxic xenobiotics and endogenous compounds. With regard to the components of MCODE 4, GCK helps to facilitate the uptake and conversion of glucose by acting as an insulin-sensitive 
364

365

366

367

368

369

370

371

372

373

374

375

376

377

378

379

380

381

382

383

384

385

386

387

388

389

390

391

392

393

394

395

396

397

398

399

400

401

402

determinant of hepatic-glucose usage (Velho et al. 1996) and OTC catalyzes the second step of the urea cycle (Horwich et al. 1984). With respect to the components of MCODE 6, it has been reported that CCL20 facilitates $\mathrm{T}_{\text {reg }}$ activity in advanced HCC (Li \& Liu 2016).

We explored the association between TICCs and DUSP12 expression. DUSP 12 expression was positively correlated with the abundance of tumor-infiltrating CD4+ T cells, macrophages, neutrophils, dendritic cells, and expression of the immune-checkpoint moieties HARVC2, TIGIT, CTLA4 and PDCD1. Increased expression of these immune-checkpoint moieties denoted a phenotype of liver cancer associated with a poor outcome. Use of TISIDB revealed that patients in the $C 3$ immune-subgroup had the longest survival (Thorsson et al. 2018) and had the lowest expression of DUSP12 (except the C6 group, which contained only one patient). Furthermore, we investigated the ratio of various types of immune cells in total TIICs between a DUSP12-high-expression group and DUSP12-low-expression group. We showed that the infiltrating abundance of $\mathrm{T}_{\text {regs }}$ was higher in DUSP12-high-expression HCC samples compared with that in DUSP12-low-expression HCC samples. $\mathrm{T}_{\text {regs }}$ can inhibit the anti-tumor effects of immune cells and facilitate immune evasion by liver-cancer cells (Jiang et al. 2017; Langhans et al. 2019). This phenomenon may be one of the reasons why patients with high expression of DUSP12 experience rapid progression of disease and have a shorter survival time.

\section{Conclusions}

We propose that DUSP12 has a critical role in the tumorigenesis and progression of HCC. DUSP12 could be a potential target for curing liver cancer.

\section{Acknowledgments}

The results of this study are based on the online databases Ualcan, GEPIA, HCCDB, KaplanMeier Plotter, TIMER, HPA, CCLE, TISIDB, CIBERSORT, cBioPortal, Metascape as well as DepMap. We thank the contributors who provided these databases/resources.

\section{Funding}

None.

\section{Competing interests}

There are no competing interests declared for all of the authors.

\section{Author contributions}

Miao and Xue designed and conducted this study and prepared the manuscript. Zhang and Pan were in charge of collecting and analyzing data. Ju and Zhou participated in research design, data analyses, and manuscript preparation.

\section{Data availability}


403

404

405

406

407

408

409

410

411

412

413

414

415

416

417

418

419

420

421

422

423

424

425

426

427

428

429

430

431

432

433

434

435

436

437

438

439

440

441

442

443

444

445

446

447

448

All data relevant to this work are available from public databases.

\section{Supplementary information}

Table S1. The top positively correlated genes in TCGA dataset for DUSP12 (Pearson correlation coefficient $>=0.3$ ).

Table S2. The top negatively correlated genes in TCGA dataset for DUSP12 (Pearson correlation coefficient $<=-0.3$ ).

Figure S1. DUSP12 expression in HCC and normal liver tissues in ICGC-LIRI-JP and GSE14520 cohorts. (A) ICGC-LIRI-JP. (B) GSE14520. ${ }^{* * * P}<0.0001$.

Figure S2. Dependency of DUSP12 in HCC cell lines.

\section{References}

Agundez JAG. 2004. Cytochrome P450 gene polymorphism and cancer. Current drug metabolism 5:211-224.

Bray F, Ferlay J, Soerjomataram I, Siegel RL, Torre LA, and Jemal A. 2018. Global cancer statistics 2018: GLOBOCAN estimates of incidence and mortality worldwide for 36 cancers in 185 countries. CA: A Cancer Journal for Clinicians 68:394-424. https://doi.org/10.3322/caac.21492

Broad D. 2021. DepMap 21Q2 Public.

Cain EL, Braun SE, and Beeser A. 2011. Characterization of a human cell line stably overexpressing the candidate oncogene, dual specificity phosphatase 12 . PloS one 6:e18677-e18677. 10.1371/journal.pone.0018677

Cerami E, Gao J, Dogrusoz U, Gross BE, Sumer SO, Aksoy BA, Jacobsen A, Byrne CJ, Heuer ML, Larsson E, Antipin Y, Reva B, Goldberg AP, Sander C, and Schultz N. 2012. The cBio Cancer Genomics Portal: An Open Platform for Exploring Multidimensional Cancer Genomics Data. Cancer Discovery 2:401. 10.1158/2159-8290.CD-12-0095

Chandrashekar DS, Bashel B, Balasubramanya SAH, Creighton CJ, Ponce-Rodriguez I, Chakravarthi BVSK, and Varambally S. 2017. UALCAN: A Portal for Facilitating Tumor Subgroup Gene Expression and Survival Analyses. Neoplasia 19:649-658. https://doi.org/10.1016/j.neo.2017.05.002

Chen W-Q, Zheng R, Baade P, Zhang S, Zeng H, Bray F, Jenber A, and Yu XQ. 2016. Cancer statistics in China. 2016:115-132.

Cheng S, Jiang X, Ding C, Du C, Owusu-Ansah KG, Weng X, Hu W, Peng C, Lv Z, Tong R, Xiao H, Xie H, Zhou L, Wu J, and Zheng S. 2016. Expression and Critical Role of Interleukin Enhancer Binding Factor 2 in Hepatocellular Carcinoma. International journal of molecular sciences 17. 10.3390/ijms17081373

Cho SSL, Han J, James SJ, Png CW, Weerasooriya M, Alonso S, and Zhang Y. 2017. DualSpecificity Phosphatase 12 Targets p38 MAP Kinase to Regulate Macrophage Response to Intracellular Bacterial Infection. Frontiers in immunology 8:1259. 10.3389/fimmu.2017.01259

Fei Q, Shang K, Zhang J, Chuai S, Kong D, Zhou T, Fu S, Liang Y, Li C, Chen Z, Zhao Y, Yu Z, Huang Z, Hu M, Ying H, Chen Z, Zhang Y, Xing F, Zhu J, Xu H, Zhao K, Lu C, Atadja P, Xiao Z-X, Li E, and Shou J. 2015. Histone methyltransferase SETDB1 regulates liver cancer cell growth through methylation of p53. Nature communications 6:8651. 10.1038/ncomms 9651 
449

450

451

452

453

454

455

456

457

458

459

460

461

462

463

464

465

466

467

468

469

470

471

472

473

474

475

476

477

478

479

480

481

482

483

484

485

486

487

488

489

490

491

492

493

494

495

496

497
Ferlay J, Soerjomataram I, Dikshit R, Eser S, Mathers C, Rebelo M, Parkin DM, Forman D, and Bray F. 2015. Cancer incidence and mortality worldwide: Sources, methods and major patterns in GLOBOCAN 2012. International Journal of Cancer 136:E359-E386. 10.1002/ijc. 29210

Fitzmorris P, Shoreibah M, Anand BS, and Singal AK. 2015. Management of hepatocellular carcinoma. Journal of Cancer Research and Clinical Oncology 141:861-876. 10.1007/s00432-014-1806-0

Gao J, Aksoy BA, Dogrusoz U, Dresdner G, Gross B, Sumer SO, Sun Y, Jacobsen A, Sinha R, Larsson E, Cerami E, Sander C, and Schultz N. 2013. Integrative analysis of complex cancer genomics and clinical profiles using the cBioPortal. Science signaling 6:pl1. 10.1126/scisignal.2004088

Ghandi M, Huang FW, Jané-Valbuena J, Kryukov GV, Lo CC, McDonald ER, Barretina J, Gelfand ET, Bielski CM, Li H, Hu K, Andreev-Drakhlin AY, Kim J, Hess JM, Haas BJ, Aguet F, Weir BA, Rothberg MV, Paolella BR, Lawrence MS, Akbani R, Lu Y, Tiv HL, Gokhale PC, de Weck A, Mansour AA, Oh C, Shih J, Hadi K, Rosen Y, Bistline J, Venkatesan K, Reddy A, Sonkin D, Liu M, Lehar J, Korn JM, Porter DA, Jones MD, Golji J, Caponigro G, Taylor JE, Dunning CM, Creech AL, Warren AC, McFarland JM, Zamanighomi M, Kauffmann A, Stransky N, Imielinski M, Maruvka YE, Cherniack AD, Tsherniak A, Vazquez F, Jaffe JD, Lane AA, Weinstock DM, Johannessen CM, Morrissey MP, Stegmeier F, Schlegel R, Hahn WC, Getz G, Mills GB, Boehm JS, Golub TR, Garraway LA, and Sellers WR. 2019. Next-generation characterization of the Cancer Cell Line Encyclopedia. Nature 569:503-508. 10.1038/s41586-019-1186-3

Goldman MJ, Craft B, Hastie M, Repečka K, McDade F, Kamath A, Banerjee A, Luo Y, Rogers D, Brooks AN, Zhu J, and Haussler D. 2020. Visualizing and interpreting cancer genomics data via the Xena platform. Nature Biotechnology 38:675-678. 10.1038/s41587-020-0546-8

Gratias S, Schüler A, Hitpass LK, Stephan H, Rieder H, Schneider S, Horsthemke B, and Lohmann DR. 2005. Genomic gains on chromosome 1q in retinoblastoma: consequences on gene expression and association with clinical manifestation. International Journal of Cancer 116:555-563.

Guan KL, Broyles SS, and Dixon JE. 1991. A Tyr/Ser protein phosphatase encoded by vaccinia virus. Nature 350:359-362.

Hirai M, Yoshida S, Kashiwagi H, Kawamura T, Ishikawa T, Kaneko M, Ohkawa H, Nakagawara A, Miwa M, and Uchida K. 1999. 1q23 gain is associated with progressive neuroblastoma resistant to aggressive treatment. Genes, chromosomes \& cancer 25:261-269.

Horwich AL, Fenton WA, Williams KR, Kalousek F, Kraus JP, Doolittle RF, Konigsberg W, and Rosenberg LE. 1984. Structure and expression of a complementary DNA for the nuclear coded precursor of human mitochondrial ornithine transcarbamylase. Science (New York, NY) 224:1068-1074.

Huang Z, Wu L-M, Zhang J-L, Sabri A, Wang S-J, Qin G-J, Guo C-Q, Wen H-T, Du B-B, Zhang D-H, Kong L-Y, Tian X-Y, Yao R, Li Y-P, Liang C, Li P-C, Wang Z, Guo J-Y, Li L, Dong J-Z, and Zhang Y-Z. 2019. Dual Specificity Phosphatase 12 Regulates Hepatic Lipid Metabolism Through Inhibition of the Lipogenesis and Apoptosis Signal-Regulating Kinase 1 Pathways. Hepatology (Baltimore, Md) 70:1099-1118. 10.1002/hep.30597

Jiang R, Tang J, Chen Y, Deng L, Ji J, Xie Y, Wang K, Jia W, Chu W-M, and Sun B. 2017. The long noncoding RNA Inc-EGFR stimulates T-regulatory cells differentiation thus promoting hepatocellular carcinoma immune evasion. Nature communications 8:15129. 10.1038/ncomms15129 
498

499

500

501

502

503

504

505

506

507

508

509

510

511

512

513

514

515

516

517

518

519

520

521

522

523

524

525

526

527

528

529

530

531

532

533

534

535

536

537

538

539

540

541

542

543

544

545

546

547

548
Jung Y-D, Cho JH, Park S, Kang M, Park S-J, Choi DH, Jeong M, Park KC, Yeom YI, and Lee DC. 2019. Lactate Activates the E2F Pathway to Promote Cell Motility by Up-Regulating Microtubule Modulating Genes. Cancers 11. 10.3390/cancers 11030274

Komatsu S, Takenobu H, Ozaki T, Ando K, Koida N, Suenaga Y, Ichikawa T, Hishiki T, Chiba T, Iwama A, Yoshida H, Ohnuma N, Nakagawara A, and Kamijo T. 2009. Plk1 regulates liver tumor cell death by phosphorylation of TAp63. Oncogene 28:3631-3641. 10.1038/onc.2009.216

Langhans B, Nischalke HD, Krämer B, Dold L, Lutz P, Mohr R, Vogt A, Toma M, Eis-Hübinger AM, Nattermann J, Strassburg CP, Gonzalez-Carmona MA, and Spengler U. 2019. Role of regulatory $T$ cells and checkpoint inhibition in hepatocellular carcinoma. Cancer immunology, immunotherapy : CII 68:2055-2066. 10.1007/s00262-019-02427-4

Li B, Severson E, Pignon J-C, Zhao H, Li T, Novak J, Jiang P, Shen H, Aster JC, Rodig S, Signoretti S, Liu JS, and Liu XS. 2016. Comprehensive analyses of tumor immunity: implications for cancer immunotherapy. Genome Biology 17:174. 10.1186/s13059-0161028-7

Li T, Fan J, Wang B, Traugh N, Chen Q, Liu JS, Li B, and Liu XS. 2017. TIMER: A Web Server for Comprehensive Analysis of Tumor-Infiltrating Immune Cells. Cancer Research 77:e108. 10.1158/0008-5472.CAN-17-0307

Li WM, and Liu HR. 2016. CCL20-CCR6 Cytokine Network Facilitate Treg Activity in Advanced Grades and Metastatic Variants of Hepatocellular Carcinoma. Scandinavian journal of immunology 83:33-37. 10.1111/sji.12367

Li X, Huang W, Huang W, Wei T, Zhu W, Chen G, and Zhang J. 2020. Kinesin family members KIF2C/4A/10/11/14/18B/20A/23 predict poor prognosis and promote cell proliferation in hepatocellular carcinoma. American journal of translational research 12:1614-1639.

Li Y, Zhu Z, Zhang S, Yu D, Yu H, Liu L, Cao X, Wang L, Gao H, and Zhu M. 2011. ShRNAtargeted centromere protein $\mathrm{A}$ inhibits hepatocellular carcinoma growth. PloS one 6:e17794. 10.1371/journal.pone.0017794

Lian Q, Wang S, Zhang G, Wang D, Luo G, Tang J, Chen L, and Gu J. 2018. HCCDB: A Database of Hepatocellular Carcinoma Expression Atlas. Genomics, proteomics \& bioinformatics 16:269-275. 10.1016/j.gpb.2018.07.003

Liu L-L, Zhu J-M, Yu X-N, Zhu H-R, Shi X, Bilegsaikhan E, Guo H-Y, Wu J, and Shen X-Z. 2019a. UBE2T promotes proliferation via G2/M checkpoint in hepatocellular carcinoma. Cancer management and research 11:8359-8370. 10.2147/CMAR.S202631

Liu L-P, Yang M, Peng Q-Z, Li M-Y, Zhang Y-S, Guo Y-H, Chen Y, and Bao S-Y. 2017. UBE2T promotes hepatocellular carcinoma cell growth via ubiquitination of p53. Biochemical and biophysical research communications 493:20-27. 10.1016/j.bbrc.2017.09.091

Liu Y, Zhang X, Lin J, Chen Y, Qiao Y, Guo S, Yang Y, Zhu G, Pan Q, Wang J, and Sun F. 2019b. CCT3 acts upstream of YAP and TFCP2 as a potential target and tumour biomarker in liver cancer. Cell death \& disease 10:644. 10.1038/s41419-019-1894-5

Llovet JM, Montal R, Sia D, and Finn RS. 2018. Molecular therapies and precision medicine for hepatocellular carcinoma. Nature reviews Clinical oncology 15:599-616. 10.1038/s41571-018-0073-4

Lohitesh K, Chowdhury R, and Mukherjee S. 2018. Resistance a major hindrance to chemotherapy in hepatocellular carcinoma: an insight. Cancer Cell International 18:44. 10.1186/s12935-018-0538-7

Long J, Zhang L, Wan X, Lin J, Bai Y, Xu W, Xiong J, and Zhao H. 2018. A four-gene-based prognostic model predicts overall survival in patients with hepatocellular carcinoma. Journal of cellular and molecular medicine 22:5928-5938. 10.1111/jcmm.13863

Luo W, Liao M, Liao Y, Chen X, Huang C, Fan J, and Liao W. 2018. The role of kinesin KIF18A in the invasion and metastasis of hepatocellular carcinoma. World journal of surgical oncology 16:36. 10.1186/s12957-018-1342-5

Peer) reviewing PDF | (2021:05:61090:1:1:NEW 13 Jul 2021) 
549

550

551

552

553

554

555

556

557

558

559

560

561

562

563

564

565

566

567

568

569

570

571

572

573

574

575

576

577

578

579

580

581

582

583

584

585

586

587

588

589

590

591

592

593

594

595

596

597

598

599

Mendrzyk F, Korshunov A, Benner A, Toedt G, Pfister S, Radlwimmer B, and Lichter P. 2006. Identification of gains on $1 \mathrm{q}$ and epidermal growth factor receptor overexpression as independent prognostic markers in intracranial ependymoma. Clinical cancer research : an official journal of the American Association for Cancer Research 12:2070-2079.

Menyhárt O, Nagy Á, and Győrffy B. 2018. Determining consistent prognostic biomarkers of overall survival and vascular invasion in hepatocellular carcinoma. Royal Society open science 5:181006. 10.1098/rsos.181006

Newman AM, Steen CB, Liu CL, Gentles AJ, Chaudhuri AA, Scherer F, Khodadoust MS, Esfahani MS, Luca BA, Steiner D, Diehn M, and Alizadeh AA. 2019. Determining cell type abundance and expression from bulk tissues with digital cytometry. Nature Biotechnology 37:773-782. 10.1038/s41587-019-0114-2

Patterson KI, Brummer T, O'Brien PM, and Daly RJ. 2009. Dual-specificity phosphatases: critical regulators with diverse cellular targets. The Biochemical journal 418:475-489.

Ru B, Wong CN, Tong Y, Zhong JY, Zhong SsW, Wu WC, Chu KC, Wong CY, Lau CY, Chen I, Chan NW, and Zhang J. 2019. TISIDB: an integrated repository portal for tumor-immune system interactions. Bioinformatics 35:4200-4202. 10.1093/bioinformatics/btz210

Sharda PR, Bonham CA, Mucaki EJ, Butt Z, and Vacratsis PO. 2009. The dual-specificity phosphatase hYVH1 interacts with $\mathrm{Hsp} 70$ and prevents heat-shock-induced cell death. The Biochemical journal 418:391-401. 10.1042/BJ20081484

Tang Z, Li C, Kang B, Gao G, Li C, and Zhang Z. 2017. GEPIA: a web server for cancer and normal gene expression profiling and interactive analyses. Nucleic Acids Research 45:W98-W102. 10.1093/nar/gkx247

Thorsson V, Gibbs DL, Brown SD, Wolf D, Bortone DS, Ou Yang T-H, Porta-Pardo E, Gao GF, Plaisier CL, Eddy JA, Ziv E, Culhane AC, Paull EO, Sivakumar IKA, Gentles AJ, Malhotra R, Farshidfar F, Colaprico A, Parker JS, Mose LE, Vo NS, Liu J, Liu Y, Rader J, Dhankani V, Reynolds SM, Bowlby R, Califano A, Cherniack AD, Anastassiou D, Bedognetti D, Mokrab Y, Newman AM, Rao A, Chen K, Krasnitz A, Hu H, Malta TM, Noushmehr H, Pedamallu CS, Bullman S, Ojesina Al, Lamb A, Zhou W, Shen H, Choueiri TK, Weinstein JN, Guinney J, Saltz J, Holt RA, Rabkin CS, Lazar AJ, Serody JS, Demicco EG, Disis ML, Vincent BG, and Shmulevich I. 2018. The Immune Landscape of Cancer. Immunity 48. 10.1016/j.immuni.2018.03.023

Uhlén M, Fagerberg L, Hallström BM, Lindskog C, Oksvold P, Mardinoglu A, Sivertsson A , Kampf C, Sjöstedt E, Asplund A, Olsson I, Edlund K, Lundberg E, Navani S, Szigyarto CA-K, Odeberg J, Djureinovic D, Takanen JO, Hober S, Alm T, Edqvist P-H, Berling H, Tegel H, Mulder J, Rockberg J, Nilsson P, Schwenk JM, Hamsten M, von Feilitzen K, Forsberg M, Persson L, Johansson F, Zwahlen M, von Heijne G, Nielsen J, and Pontén F. 2015. Tissue-based map of the human proteome. Science 347:1260419. $10.1126 /$ science. 1260419

Uhlen M, Zhang C, Lee S, Sjöstedt E, Fagerberg L, Bidkhori G, Benfeitas R, Arif M, Liu Z, Edfors F, Sanli K, von Feilitzen K, Oksvold P, Lundberg E, Hober S, Nilsson P, Mattsson J, Schwenk JM, Brunnström H, Glimelius B, Sjöblom T, Edqvist P-H, Djureinovic D, Micke $P$, Lindskog $C$, Mardinoglu A, and Ponten F. 2017. A pathology atlas of the human cancer transcriptome. Science 357:eaan2507. 10.1126/science.aan2507

Velho G, Petersen KF, Perseghin G, Hwang JH, Rothman DL, Pueyo ME, Cline GW, Froguel P, and Shulman Gl. 1996. Impaired hepatic glycogen synthesis in glucokinase-deficient (MODY-2) subjects. The Journal of clinical investigation 98:1755-1761.

Wei X, You X, Zhang J, and Zhou C. 2019. MicroRNA-1305 Inhibits the Stemness of LCSCs and Tumorigenesis by Repressing the UBE2T-Dependent Akt-Signaling Pathway. Molecular therapy Nucleic acids 16:721-732. 10.1016/j.omtn.2019.04.013

Wu CX, Wang XQ, Chok SH, Man K, Tsang SHY, Chan ACY, Ma KW, Xia W, and Cheung TT. 2018. Blocking CDK1/PDK1/ $\beta$-Catenin signaling by CDK1 inhibitor RO3306 increased

Peer) reviewing PDF | (2021:05:61090:1:1:NEW 13 Jul 2021) 
600

601

602

603

604

605

606

607

608

609

610

611

612

613

614

615

616

617

618

619

620

621

622

623

624

625

626

627

628

629

630

631

632

633

634

635

636

637

638

639

640

641

642

643

644

645

646 the efficacy of sorafenib treatment by targeting cancer stem cells in a preclinical model of hepatocellular carcinoma. Theranostics 8:3737-3750. 10.7150/thno.25487

Zhang H, Diab A, Fan H, Mani SKK, Hullinger R, Merle P, and Andrisani O. 2015. PLK1 and HOTAIR Accelerate Proteasomal Degradation of SUZ12 and ZNF198 during Hepatitis B Virus-Induced Liver Carcinogenesis. Cancer Research 75:2363-2374. 10.1158/00085472.CAN-14-2928

Zhou Y, Zhou B, Pache L, Chang M, Khodabakhshi AH, Tanaseichuk O, Benner C, and Chanda SK. 2019. Metascape provides a biologist-oriented resource for the analysis of systemslevel datasets. Nature communications 10:1523. 10.1038/s41467-019-09234-6

Zhu Q, Li N, Zeng X, Han Q, Li F, Yang C, Lv Y, Zhou Z, and Liu Z. 2015. Hepatocellular carcinoma in a large medical center of China over a 10 -year period: evolving therapeutic option and improving survival. Oncotarget 6:4440-4450. 10.18632/oncotarget.2913

Agundez JAG. 2004. Cytochrome P450 gene polymorphism and cancer. Current Drug Metabolism 5:211-224.

Bray F, Ferlay J, Soerjomataram I, Siegel RL, Torre LA, Jemal A. 2018. Global cancer statistics 2018: GLOBOCAN estimates of incidence and mortality worldwide for 36 cancers in 185 countries. CA: 68:394-424. https://doi.org/10.3322/caac.21492

Cain EL, Braun SE, Beeser A. 2011. Characterization of a human cell line stably over-expressing the candidate oncogene, dual specificity phosphatase 12 . PloS One 6:e18677-e18677. 10.1371/journal.pone.0018677

Cerami E, Gao J, Dogrusoz U, Gross BE, Sumer SO, Aksoy BA, Jacobsen A, Byrne CJ, Heuer ML, Larsson E, Antipin Y, Reva B, Goldberg AP, Sander C, Schultz N. 2012. The cBio Cancer Genomics Portal: an open platform for exploring multidimensional cancer genomics data. Cancer Discovery 2:401. 10.1158/2159-8290.CD-12-0095

Chandrashekar DS, Bashel B, Balasubramanya SAH, Creighton CJ, Ponce-Rodriguez I, Chakravarthi BVSK, Varambally S. 2017. UALCAN: a portal for facilitating tumor subgroup gene expression and survival analyses. Neoplasia 19:649-658. https://doi.org/10.1016/j.neo.2017.05.002

Chen W-Q, Zheng R, Baade P, Zhang S, Zeng H, Bray F, Jenber A, Yu XQ. 2016. Cancer statistics in China. CA Cancer J Clin 66(2):115-132.

Cheng S, Jiang X, Ding C, Du C, Owusu-Ansah KG, Weng X, Hu W, Peng C, Lv Z, Tong R, Xiao H, Xie H, Zhou L, Wu J, Zheng S. 2016. Expression and critical role of interleukin enhancer binding factor 2 in hepatocellular carcinoma. International Journal of Molecular Sciences 17(8):1373. 10.3390/ijms17081373

Cho SSL, Han J, James SJ, Png CW, Weerasooriya M, Alonso S, Zhang Y. 2017. Dualspecificity phosphatase 12 targets p38 MAP kinase to regulate macrophage response to intracellular bacterial infection. Frontiers in Immunology 8:1259. 10.3389/fimmu.2017.01259

Fei Q, Shang K, Zhang J, Chuai S, Kong D, Zhou T, Fu S, Liang Y, Li C, Chen Z, Zhao Y, Yu Z, Huang Z, Hu M, Ying H, Chen Z, Zhang Y, Xing F, Zhu J, Xu H, Zhao K, Lu C, Atadja P, Xiao Z-X, Li E, Shou J. 2015. Histone methyltransferase SETDB1 regulates liver cancer cell growth through methylation of p53. Nature Communications 6:8651. 10.1038 /ncomms9651

Ferlay J, Soerjomataram I, Dikshit R, Eser S, Mathers C, Rebelo M, Parkin DM, Forman D, Bray F. 2015. Cancer incidence and mortality worldwide: sources, methods and major patterns in GLOBOCAN 2012. International Journal of Cancer 136:E359-E386. $10.1002 /$ ijc. 29210

Peer] reviewing PDF | (2021:05:61090:1:1:NEW 13 Jul 2021) 
647 Fitzmorris P, Shoreibah M, Anand BS, Singal AK. 2015. Management of hepatocellular

648

649

650

651

652

653

654

655

656

657

658

659

660

661

662

663

664

665

666

667

668

669

670

671

672

673

674

675

676

677

678

679

680

681

682

683

684

685

686

687

688

689

690

691

carcinoma. Journal of Cancer Research and Clinical Oncology 141:861-876. 10.1007/s00432-014-1806-0

Gao J, Aksoy BA, Dogrusoz U, Dresdner G, Gross B, Sumer SO, Sun Y, Jacobsen A, Sinha R, Larsson E, Cerami E, Sander C, Schultz N. 2013. Integrative analysis of complex cancer genomics and clinical profiles using the cBioPortal. Science Signaling 6:p11. 10.1126/scisignal.2004088

Ghandi M, Huang FW, Jané-Valbuena J, Kryukov GV, Lo CC, McDonald ER, Barretina J, Gelfand ET, Bielski CM, Li H, Hu K, Andreev-Drakhlin AY, Kim J, Hess JM, Haas BJ, Aguet F, Weir BA, Rothberg MV, Paolella BR, Lawrence MS, Akbani R, Lu Y, Tiv HL, Gokhale PC, de Weck A, Mansour AA, Oh C, Shih J, Hadi K, Rosen Y, Bistline J, Venkatesan K, Reddy A, Sonkin D, Liu M, Lehar J, Korn JM, Porter DA, Jones MD, Golji J, Caponigro G, Taylor JE, Dunning CM, Creech AL, Warren AC, McFarland JM, Zamanighomi M, Kauffmann A, Stransky N, Imielinski M, Maruvka YE, Cherniack AD, Tsherniak A, Vazquez F, Jaffe JD, Lane AA, Weinstock DM, Johannessen CM, Morrissey MP, Stegmeier F, Schlegel R, Hahn WC, Getz G, Mills GB, Boehm JS, Golub TR, Garraway LA, Sellers WR. 2019. Next-generation characterization of the Cancer Cell Line Encyclopedia. Nature 569:503-508. 10.1038/s41586-019-1186-3

Goldman MJ, Craft B, Hastie M, Repečka K, McDade F, Kamath A, Banerjee A, Luo Y, Rogers D, Brooks AN, Zhu J, Haussler D. 2020. Visualizing and interpreting cancer genomics data via the Xena platform. Nature Biotechnology 38:675-678. 10.1038/s41587-0200546-8

Gratias S, Schüler A, Hitpass LK, Stephan H, Rieder H, Schneider S, Horsthemke B, Lohmann DR. 2005. Genomic gains on chromosome 1q in retinoblastoma: consequences on gene expression and association with clinical manifestation. International Journal of Cancer 116:555-563.

Guan KL, Broyles SS, Dixon JE. 1991. A Tyr/Ser protein phosphatase encoded by vaccinia virus. Nature 350:359-362.

Hirai M, Yoshida S, Kashiwagi H, Kawamura T, Ishikawa T, Kaneko M, Ohkawa H, Nakagawara A, Miwa M, Uchida K. 1999. 1q23 gain is associated with progressive neuroblastoma resistant to aggressive treatment. Genes, Chromosomes \& Cancer 25:261269.

Horwich AL, Fenton WA, Williams KR, Kalousek F, Kraus JP, Doolittle RF, Konigsberg W, Rosenberg LE. 1984. Structure and expression of a complementary DNA for the nuclear coded precursor of human mitochondrial ornithine transcarbamylase. Science (New York, NY) 224:1068-1074.

Huang Z, Wu L-M, Zhang J-L, Sabri A, Wang S-J, Qin G-J, Guo C-Q, Wen H-T, Du B-B, Zhang D-H, Kong L-Y, Tian X-Y, Yao R, Li Y-P, Liang C, Li P-C, Wang Z, Guo J-Y, Li L, Dong J-Z, Zhang Y-Z. 2019. Dual specificity phosphatase 12 regulates hepatic lipid metabolism through inhibition of the lipogenesis and apoptosis signal-regulating kinase 1 pathways. Hepatology (Baltimore, MD) 70:1099-1118. 10.1002/hep.30597

Jiang R, Tang J, Chen Y, Deng L, Ji J, Xie Y, Wang K, Jia W, Chu W-M, Sun B. 2017. The long noncoding RNA lnc-EGFR stimulates T-regulatory cells differentiation thus promoting hepatocellular carcinoma immune evasion. Nature Communications 8:15129. $10.1038 /$ ncomms 15129

Peer] reviewing PDF | (2021:05:61090:1:1:NEW 13 Jul 2021) 
692

693

694

695

696

697

698

699

700

701

702

703

704

705

706

707

708

709

710

711

712

713

714

715

716

717

718

719

720

721

722

723

724

725

726

727

728

729

730

731

732

733

734

735

736
Jung Y-D, Cho JH, Park S, Kang M, Park S-J, Choi DH, Jeong M, Park KC, Yeom YI, Lee DC. 2019. Lactate activates the E2f pathway to promote cell motility by up-regulating microtubule modulating genes. Cancers 11(3):274. 10.3390/cancers11030274

Komatsu S, Takenobu H, Ozaki T, Ando K, Koida N, Suenaga Y, Ichikawa T, Hishiki T, Chiba T, Iwama A, Yoshida H, Ohnuma N, Nakagawara A, Kamijo T. 2009. Plk1 regulates liver tumor cell death by phosphorylation of TAp63. Oncogene 28:3631-3641. 10.1038/onc. 2009.216

Langhans B, Nischalke HD, Krämer B, Dold L, Lutz P, Mohr R, Vogt A, Toma M, Eis-Hübinger AM, Nattermann J, Strassburg CP, Gonzalez-Carmona MA, Spengler U. 2019. Role of regulatory $\mathrm{T}$ cells and checkpoint inhibition in hepatocellular carcinoma. Cancer immunology, immunotherapy 68:2055-2066. 10.1007/s00262-019-02427-4

Li B, Severson E, Pignon J-C, Zhao H, Li T, Novak J, Jiang P, Shen H, Aster JC, Rodig S, Signoretti S, Liu JS, Liu XS. 2016. Comprehensive analyses of tumor immunity: implications for cancer immunotherapy. Genome Biology 17:174. 10.1186/s13059-0161028-7

Li T, Fan J, Wang B, Traugh N, Chen Q, Liu JS, Li B, and Liu XS. 2017. TIMER: a web server for comprehensive analysis of tumor-infiltrating immune cells. Cancer Research 77:e108. 10.1158/0008-5472.CAN-17-0307

Li WM, Liu HR. 2016. CCL20-CCR6 cytokine network facilitate treg activity in advanced grades and metastatic variants of hepatocellular carcinoma. Scandinavian Journal of Immunology 83:33-37. 10.1111/sji.12367

Li X, Huang W, Huang W, Wei T, Zhu W, Chen G, Zhang J. 2020. Kinesin family members $\mathrm{KIF} 2 \mathrm{C} / 4 \mathrm{~A} / 10 / 11 / 14 / 18 \mathrm{~B} / 20 \mathrm{~A} / 23$ predict poor prognosis and promote cell proliferation in hepatocellular carcinoma. American Journal of Translational Research 12:1614-1639.

Li Y, Zhu Z, Zhang S, Yu D, Yu H, Liu L, Cao X, Wang L, Gao H, and Zhu M. 2011. shRNAtargeted centromere protein A inhibits hepatocellular carcinoma growth. PloS One 6:e17794. 10.1371/journal.pone.0017794

Lian Q, Wang S, Zhang G, Wang D, Luo G, Tang J, Chen L, and Gu J. 2018. HCCDB: a database of Hepatocellular Carcinoma Expression Atlas. Genomics, Proteomics \& Bioinformatics 16:269-275. 10.1016/j.gpb.2018.07.003

Liu L-L, Zhu J-M, Yu X-N, Zhu H-R, Shi X, Bilegsaikhan E, Guo H-Y, Wu J, Shen X-Z. 2019a. UBE2T promotes proliferation via $\mathrm{G} 2 / \mathrm{M}$ checkpoint in hepatocellular carcinoma. Cancer Management and Research 11:8359-8370. 10.2147/CMAR.S202631

Liu L-P, Yang M, Peng Q-Z, Li M-Y, Zhang Y-S, Guo Y-H, Chen Y, Bao S-Y. 2017. UBE2T promotes hepatocellular carcinoma cell growth via ubiquitination of $\mathrm{p} 53$. Biochemical and Biophysical Research Communications 493:20-27. 10.1016/j.bbrc.2017.09.091

Liu Y, Zhang X, Lin J, Chen Y, Qiao Y, Guo S, Yang Y, Zhu G, Pan Q, Wang J, Sun F. 2019b. CCT3 acts upstream of YAP and TFCP2 as a potential target and tumour biomarker in liver cancer. Cell Death \& Disease 10:644. 10.1038/s41419-019-1894-5

Llovet JM, Montal R, Sia D, Finn RS. 2018. Molecular therapies and precision medicine for hepatocellular carcinoma. Nature Reviews Clinical Oncology 15:599-616. 10.1038/s41571-018-0073-4

Lohitesh K, Chowdhury R, Mukherjee S. 2018. Resistance a major hindrance to chemotherapy in hepatocellular carcinoma: an insight. Cancer Cell International 18:44. 10.1186/s12935018-0538-7 
737

738

739

740

741

742

743

744

745

746

747

748

749

750

751

752

753

754

755

756

757

758

759

760

761

762

763

764

765

766

767

768

769

770

771

772

773

774

775

776

777

778

779

780

781

782

Long J, Zhang L, Wan X, Lin J, Bai Y, Xu W, Xiong J, Zhao H. 2018. A four-gene-based prognostic model predicts overall survival in patients with hepatocellular carcinoma. Journal of Cellular and Molecular Medicine 22:5928-5938. 10.1111/jcmm.13863

Luo W, Liao M, Liao Y, Chen X, Huang C, Fan J, Liao W. 2018. The role of kinesin KIF18A in the invasion and metastasis of hepatocellular carcinoma. World Journal of Surgical Oncology 16:36. 10.1186/s12957-018-1342-5

Mendrzyk F, Korshunov A, Benner A, Toedt G, Pfister S, Radlwimmer B, Lichter P. 2006. Identification of gains on $1 \mathrm{q}$ and epidermal growth factor receptor overexpression as independent prognostic markers in intracranial ependymoma. Clinical Cancer Research 12:2070-2079.

Menyhárt O, Nagy Á, Győrffy B. 2018. Determining consistent prognostic biomarkers of overall survival and vascular invasion in hepatocellular carcinoma. Royal Society Open Science 5:181006. 10.1098/rsos.181006

Newman AM, Steen CB, Liu CL, Gentles AJ, Chaudhuri AA, Scherer F, Khodadoust MS, Esfahani MS, Luca BA, Steiner D, Diehn M, Alizadeh AA. 2019. Determining cell type abundance and expression from bulk tissues with digital cytometry. Nature Biotechnology 37:773-782. 10.1038/s41587-019-0114-2

Papatheodorou I, Moreno P, Manning J, Fuentes AM-P, George N, Fexova S, Fonseca NA, Füllgrabe A, Green M, Huang N, Huerta L, Iqbal H, Jianu M, Mohammed S, Zhao L, Jarnuczak AF, Jupp S, Marioni J, Meyer K, Petryszak R, Prada Medina CA, TalaveraLópez C, Teichmann S, Vizcaino JA, Brazma A. 2020. Expression Atlas update: from tissues to single cells. Nucleic Acids Research 48:D77-D83. 10.1093/nar/gkz947

Patterson KI, Brummer T, O'Brien PM, Daly RJ. 2009. Dual-specificity phosphatases: critical regulators with diverse cellular targets. Biochemical Journal 418:475-489.

Ru B, Wong CN, Tong Y, Zhong JY, Zhong SSW, Wu WC, Chu KC, Wong CY, Lau CY, Chen I, Chan NW, Zhang J. 2019. TISIDB: an integrated repository portal for tumor-immune system interactions. Bioinformatics 35:4200-4202. 10.1093/bioinformatics/btz210

Sharda PR, Bonham CA, Mucaki EJ, Butt Z, Vacratsis PO. 2009. The dual-specificity phosphatase hYVH1 interacts with Hsp70 and prevents heat-shock-induced cell death. Biochemical Journal 418:391-401. 10.1042/BJ20081484

Tang Z, Li C, Kang B, Gao G, Li C, Zhang Z. 2017. GEPIA: a web server for cancer and normal gene expression profiling and interactive analyses. Nucleic Acids Research 45:W98W102. 10.1093/nar/gkx247

Thorsson V, Gibbs DL, Brown SD, Wolf D, Bortone DS, Ou Yang T-H, Porta-Pardo E, Gao GF, Plaisier CL, Eddy JA, Ziv E, Culhane AC, Paull EO, Sivakumar IKA, Gentles AJ, Malhotra R, Farshidfar F, Colaprico A, Parker JS, Mose LE, Vo NS, Liu J, Liu Y, Rader J, Dhankani V, Reynolds SM, Bowlby R, Califano A, Cherniack AD, Anastassiou D, Bedognetti D, Mokrab Y, Newman AM, Rao A, Chen K, Krasnitz A, Hu H, Malta TM, Noushmehr H, Pedamallu CS, Bullman S, Ojesina AI, Lamb A, Zhou W, Shen H, Choueiri TK, Weinstein JN, Guinney J, Saltz J, Holt RA, Rabkin CS, Lazar AJ, Serody JS, Demicco EG, Disis ML, Vincent BG, Shmulevich I. 2018. The immune landscape of cancer. Immunity 48(4):812-830.e14. 10.1016/j.immuni.2018.03.023

Uhlén M, Fagerberg L, Hallström BM, Lindskog C, Oksvold P, Mardinoglu A, Sivertsson Å, Kampf C, Sjöstedt E, Asplund A, Olsson I, Edlund K, Lundberg E, Navani S, Szigyarto CA-K, Odeberg J, Djureinovic D, Takanen JO, Hober S, Alm T, Edqvist P-H, Berling H, Tegel H, Mulder J, Rockberg J, Nilsson P, Schwenk JM, Hamsten M, von Feilitzen K,

Peer) reviewing PDF | (2021:05:61090:1:1:NEW 13 Jul 2021) 
783

784

785

786

787

788

789

790

791

792

793

794

795

796

797

798

799

800

801

802

803

804

805

806

807

808

809

810

811

812

813

814

815

816

817

818

819

820

821

822

823

824

825

826
Forsberg M, Persson L, Johansson F, Zwahlen M, von Heijne G, Nielsen J, Pontén F. 2015. Tissue-based map of the human proteome. Science 347:1260419. 10.1126/science. 1260419

Uhlen M, Zhang C, Lee S, Sjöstedt E, Fagerberg L, Bidkhori G, Benfeitas R, Arif M, Liu Z, Edfors F, Sanli K, von Feilitzen K, Oksvold P, Lundberg E, Hober S, Nilsson P, Mattsson J, Schwenk JM, Brunnström H, Glimelius B, Sjöblom T, Edqvist P-H, Djureinovic D, Micke P, Lindskog C, Mardinoglu A, Ponten F. 2017. A pathology atlas of the human cancer transcriptome. Science 357:eaan2507. 10.1126/science.aan2507

Velho G, Petersen KF, Perseghin G, Hwang JH, Rothman DL, Pueyo ME, Cline GW, Froguel P, Shulman GI. 1996. Impaired hepatic glycogen synthesis in glucokinase-deficient (MODY-2) subjects. Journal of Clinical Investigation 98:1755-1761.

Wei X, You X, Zhang J, Zhou C. 2019. microRNA-1305 inhibits the stemness of LCSCS and tumorigenesis by repressing the UBE2t-dependent Akt-signaling pathway. Molecular Therapy Nucleic Acids 16:721-732. 10.1016/j.omtn.2019.04.013

Wu CX, Wang XQ, Chok SH, Man K, Tsang SHY, Chan ACY, Ma KW, Xia W, Cheung TT. 2018. Blocking CDK1/PDK1/ $\beta$-Catenin signaling by CDK1 inhibitor RO3306 increased the efficacy of sorafenib treatment by targeting cancer stem cells in a preclinical model of hepatocellular carcinoma. Theranostics 8:3737-3750. 10.7150/thno.25487

Zhang H, Diab A, Fan H, Mani SKK, Hullinger R, Merle P, Andrisani O. 2015. PLK1 and HOTAIR accelerate proteasomal degradation of SUZ12 and ZNF198 during hepatitis B virus-induced liver carcinogenesis. Cancer Research 75:2363-2374. 10.1158/00085472.CAN-14-2928

Zhou Y, Zhou B, Pache L, Chang M, Khodabakhshi AH, Tanaseichuk O, Benner C, Chanda SK. 2019. Metascape provides a biologist-oriented resource for the analysis of systems-level datasets. Nature Communications 10:1523. 10.1038/s41467-019-09234-6

Zhu Q, Li N, Zeng X, Han Q, Li F, Yang C, Lv Y, Zhou Z, Liu Z. 2015. Hepatocellular carcinoma in a large medical center of China over a 10-year period: evolving therapeutic option and improving survival. Oncotarget 6:4440-4450. 10.18632/oncotarget.2913 
827 Figure legends

828 Figure 1. DUSP12 expression in the Ualcan database. (A) Normal vs. primary tumor. (B)

829 Ethnicity. (C) Stage. (D) Grade. (E) Nodal metastasis. (F) TP53 mutation. $* \mathrm{P}<0.05, * * \mathrm{P}<0.01$,

830

831

832

833

834

835

836

837

838

839

840

841

842

843

844

845

846

847

848

849

850

851

852

853

854

855

856

857

858

859

860

861

862

863

864

865

866

867

868

869

870

871

872 $* * * \mathrm{P}<0.001, * * * * \mathrm{P}<0.0001$

Figure 2. Analysis of gene expression in the HCCDB. (A) DUSP12 expression in 11 cohorts. (B) PPI network containing DUSP 12. (C) Heatmap for selected genes in the GO database ( $\mathrm{P}<$ 0.05). (D) Network colored by cluster. (E) Network colored by P-value. GO, gene ontology; PPI, protein-protein network.

Figure 3. DUSP12 expression in liver-cancer tissues, normal liver tissues, and liver-cancer cell lines. (A) Normal liver tissues. (B) Liver-cancer tissues. (C) Liver-cancer cell lines.

Figure 4. Survival analyses of HCC patients with high expression of DUSP12 and low expression of DUSP12. (A) OS in GEPIA. (B) DFS in GEPIA. (C) OS in Kaplan-Meier Plotter. (D) DFS in Kaplan-Meier Plotter. (E) PFS in Kaplan-Meier Plotter. (F) DSS in Kaplan-Meier Plotter. OS, overall survival; DFS, disease free survival; PFS, progression free survival; DSS, disease specific survival; GEPIA, Gene Expression Profiling Interactive Analysis.

Figure 5. Analyses of mutant status of DUSP12 in HCC. (A) Frequency of the DUSP12 mutation. (B) Frequency of mutant types. (C) mRNA expression of DUSP12 in HCC cases with various types of mutant status. (D) OS of DUSP12-altered and DUSP12-nonaltered groups. OS, overall survival.

Figure 6. Clinical features of HCC patients with or without alteration of DUSP12 expression. (A) mRNA expression of DUSP12 in HCC patients with different copy numbers. (B) Relationship between mRNA expression of DUSP12 and DUSP12 methylation. (C) AFP level at procurement in DUSP12-altered and DUSP12-nonaltered groups. (D) Fraction of genome altered in DUSP12-altered and DUSP12-nonaltered groups. (E) Histology grade in DUSP12-altered and DUSP12-nonaltered groups. AFP, alpha-fetoprotein; ${ }^{*} \mathrm{P}<0.05,{ }^{* * *} \mathrm{P}<$ 0.001 .

Figure 7. DEGs between HCC cases with altered and nonaltered DUSP12. (A) Volcano plot of DEGs between HCC cases with altered and nonaltered DUSP 12. (B) Heatmap for selected terms $(\mathrm{P}<0.05)$. (C) Network colored by cluster. (D) MCODEs of the PPI network. DEGs, differentially expressed genes; MCODEs, Minimal Common Oncology Data Elements; PPI, protein-protein network.

Figure 8. Correlation between DUSP12 expression and number of tumor-infiltrating immune cells. (A) Pearson correlation between DUSP12 expression with TIICs abundance. (B) Pearson correlation between DUSP12 expression with immune-checkpoint moieties. (C) DUSP 12 expression in HCC cases with different copy numbers. (D) DUSP 12 expression in HCC cases with different immune subtypes. TIIC, tumor infiltrating immune cells. $* \mathrm{P}<0.05,{ }^{*} \mathrm{P}<$ 0.01 .

Figure 9. Ratio of various TIICs in HCC. $* \mathrm{P}<0.05$. TIICs, tumor infiltrating immune cells. 
873

874 Figure 10. Knockdown of DUSP12 expression reduces the proliferation and migration of 875 Huh7 cells. (A) Knockdown of DUSP12 expression in Huh7 cells. (B) Proliferation of cells

876 according to the CCK8 assay. (C) Migration of cells according to the Transwell ${ }^{\mathrm{TM}}$ assay. ${ }^{* * * * \mathrm{P}}$

$877<0.0001$.

878 
Figure 1

DUSP12 expression in the Ualcan database.

DUSP12 expression in the Ualcan database. (A) Normal vs. primary tumor. (B) Ethnicity. (C) Stage. (D) Grade. (E) Nodal metastasis. (F) TP53 mutation. *P $<0.05$, **P $<0.01$, *** $<$ $0.001, * * * * P<0.0001$. 
A Expression of DUSP12 in LIHC based on Sample types $\mathbf{B}$

Expression of DUSP12 in LIHC based on patient's race

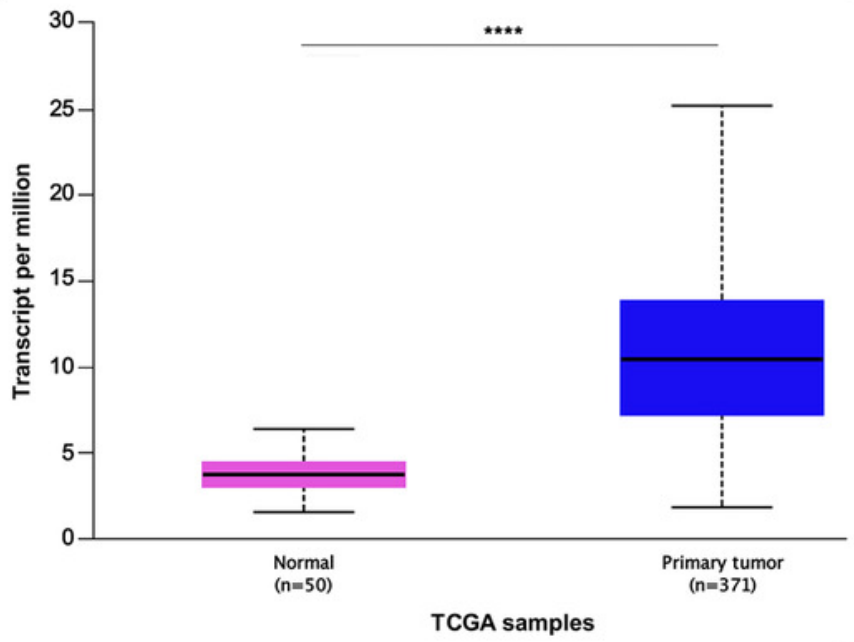

C Expression of DUSP12 in LIHC based on individual cancer stages

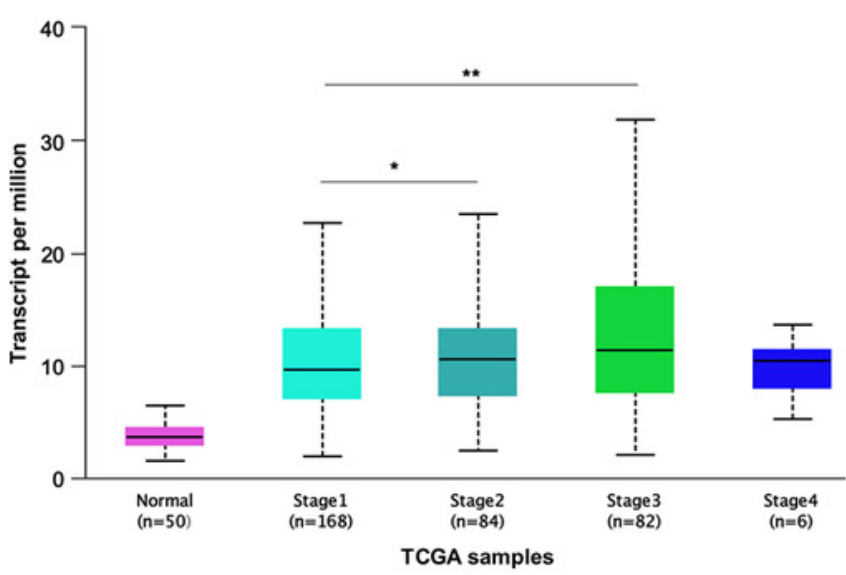

E Expression of DUSP12 in LIHC based on nodal metastasis $\mathbf{F}$ status

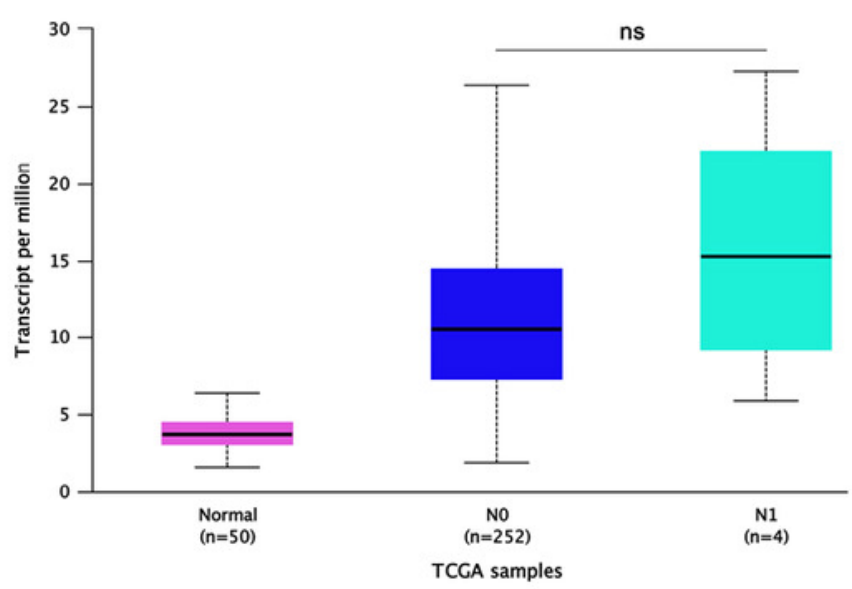

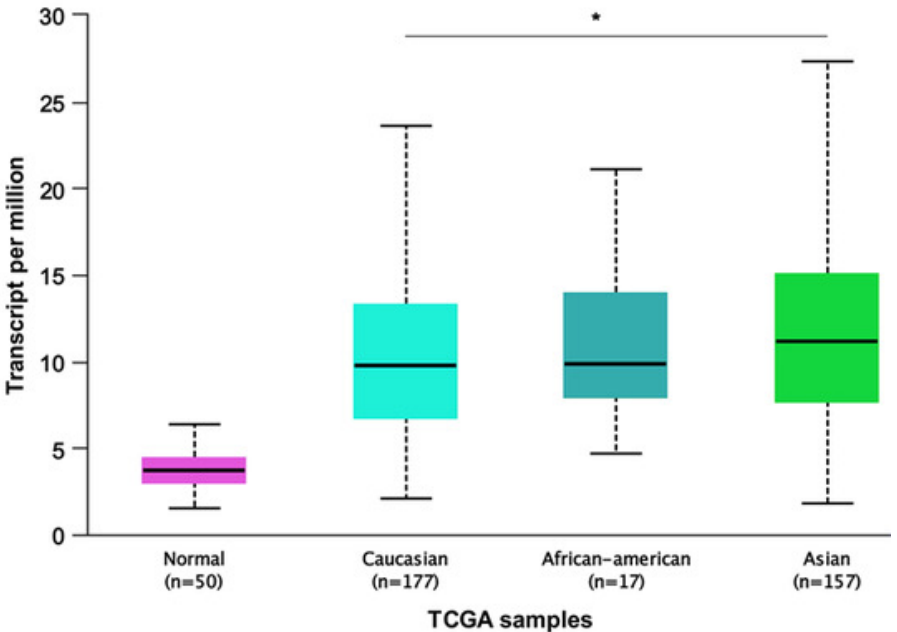

D Expression of DUSP12 in LIHC based on tumor grade

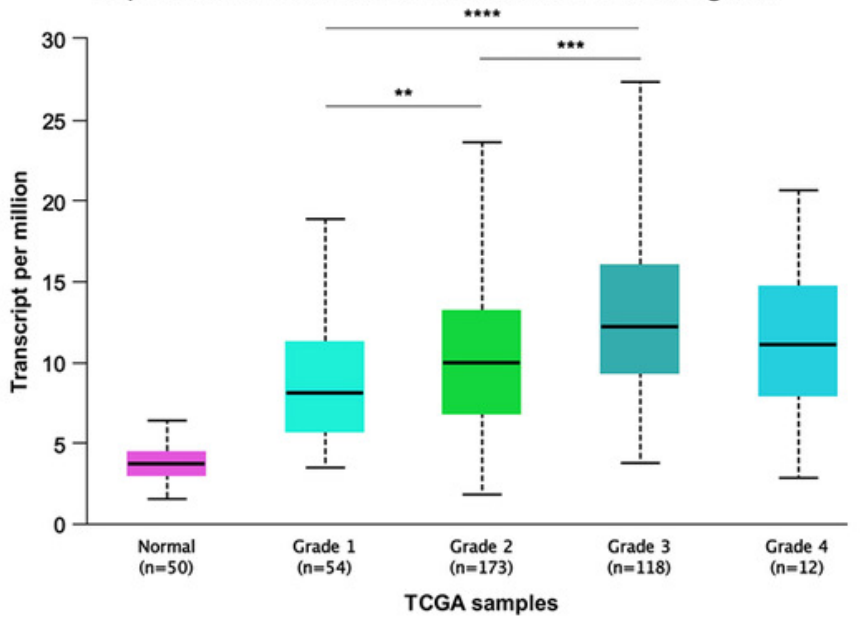

Expression of DUSP12 in LIHC based on TP53 muation status

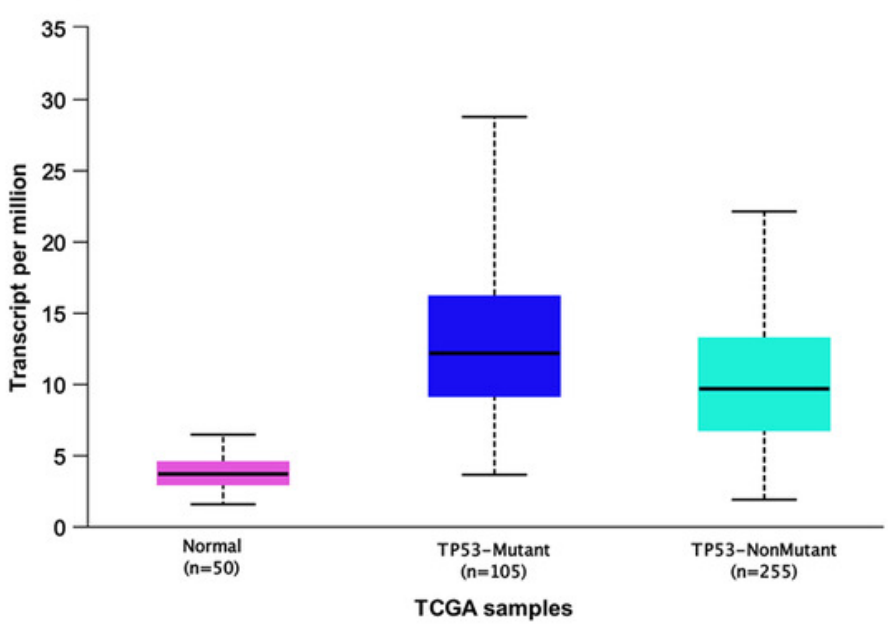


Figure 2

Analysis of gene expression in the HCCDB

Analysis of gene expression in the HCCDB. (A) DUSP12 expression in 11 cohorts. (B) PPI network containing DUSP12. (C) Heatmap for selected genes in the GO database $(P<0.05)$. (D) Network colored by cluster. (E) Network colored by P-value. GO, gene ontology; PPI, protein-protein network. 
A

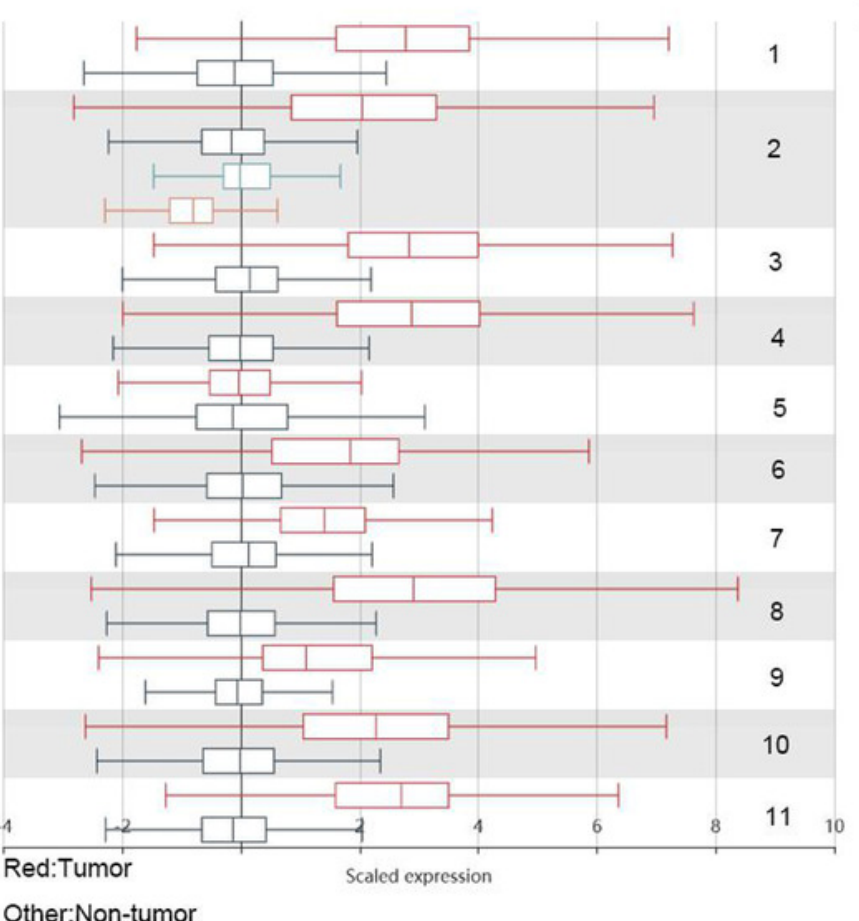

$\mathrm{C}$
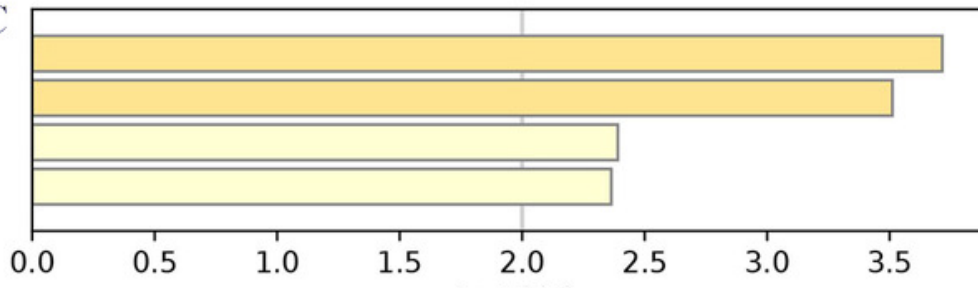

D

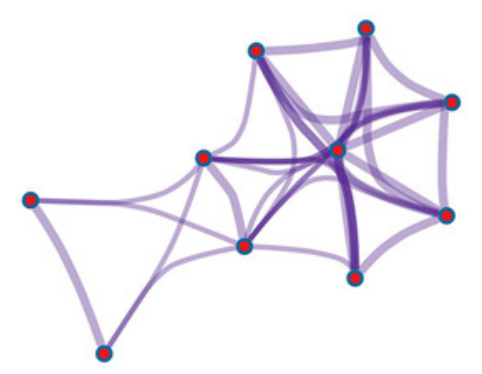

○

○

histone methylation

cullin-RING ubiquitin ligase complex

nuclear speck

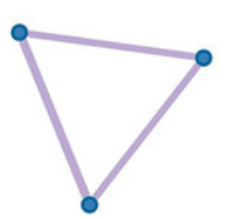

E

ubiquitin-like protein transferase activity
B

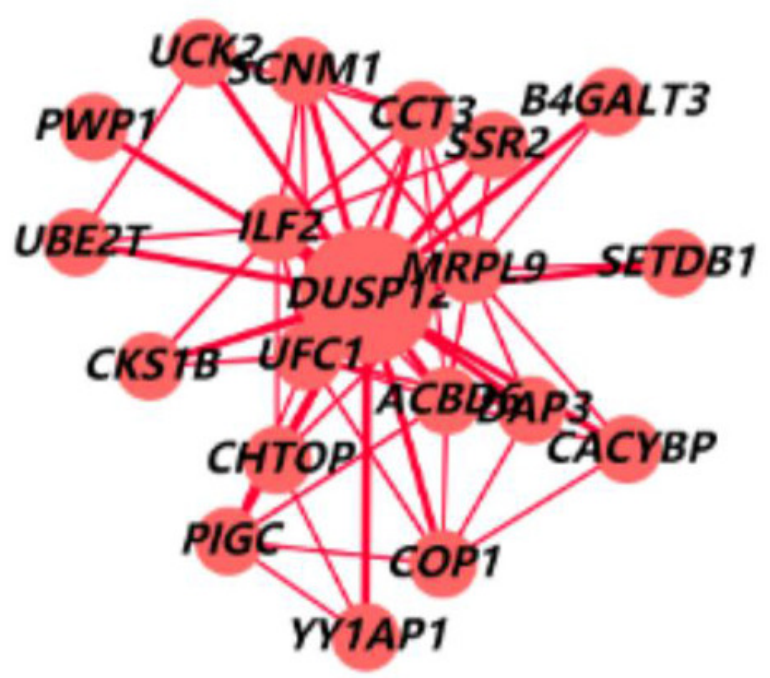

GO:0016571: histone methylation

GO:0031461: cullin-RING ubiquitin ligase complex GO:0016607: nuclear speck

GO:0019787: ubiquitin-like protein transferase activity
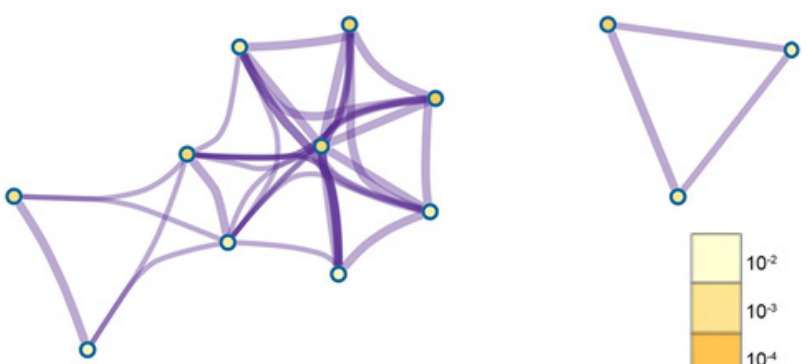

$\circ$

$\circ$

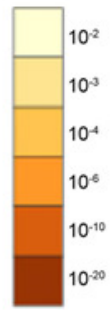


Figure 3

DUSP12 expression in liver-cancer tissues, normal liver tissues, and liver-cancer cell lines

\section{DUSP12 expression in liver-cancer tissues, normal liver tissues, and liver-cancer}

cell lines. (A) Normal liver tissues. (B) Liver-cancer tissues. (C) Liver-cancer cell lines.
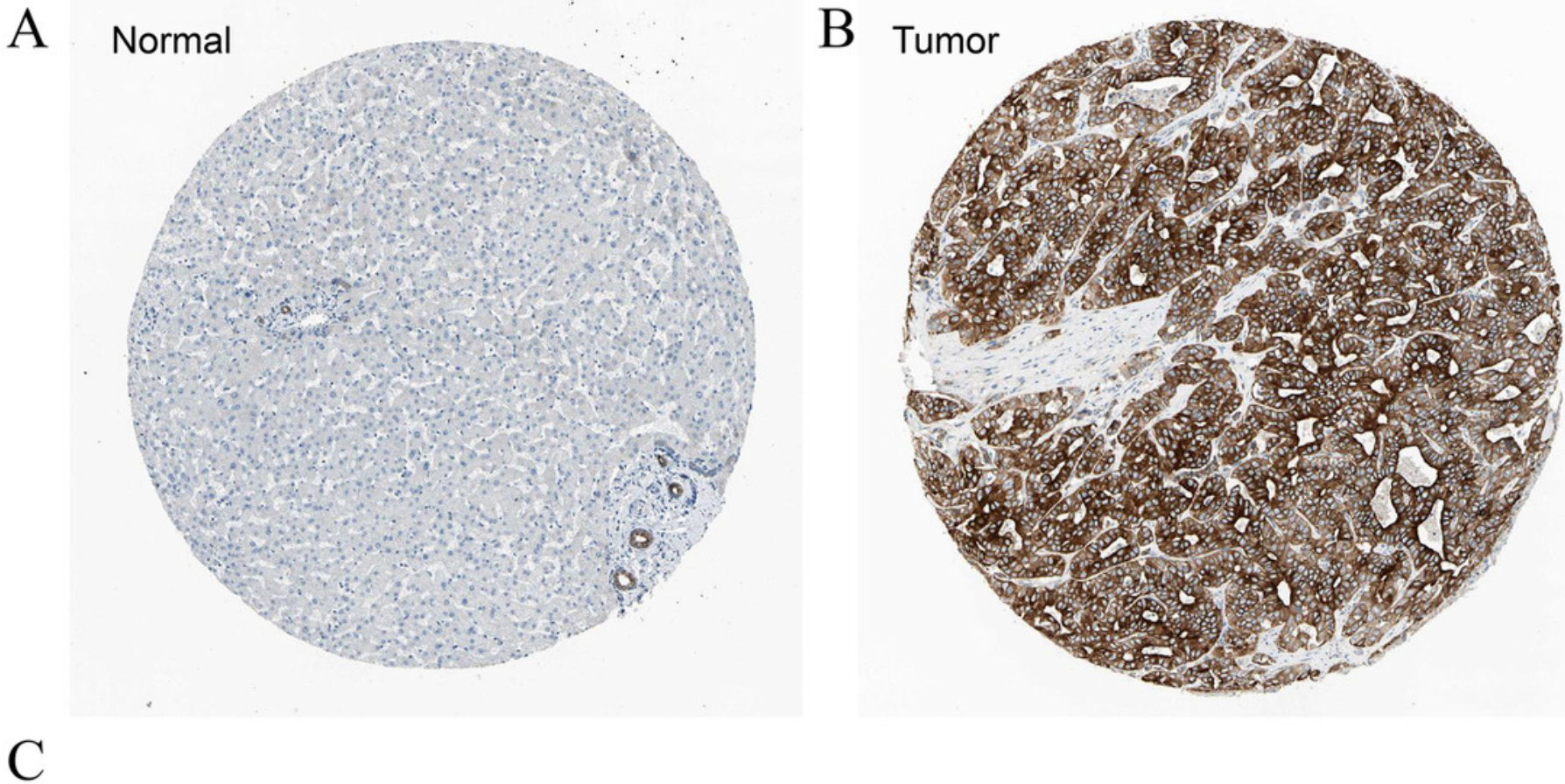

$\mathrm{C}$

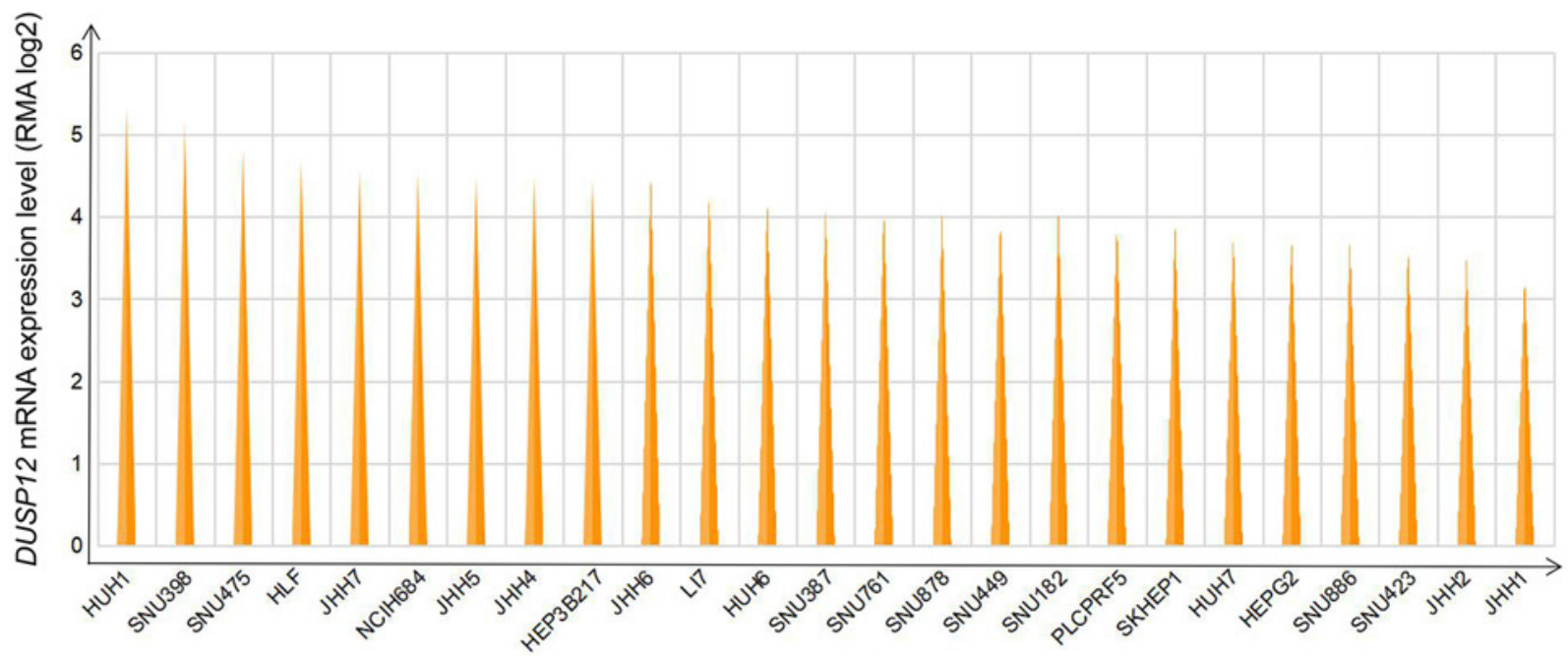

Liver cancer cell lines 


\section{Figure 4}

Survival analyses of HCC patients with high expression of DUSP12 and low expression of DUSP12

\section{Survival analyses of HCC patients with high expression of DUSP12 and low} expression of DUSP12. (A) OS in GEPIA. (B) DFS in GEPIA. (C) OS in Kaplan-Meier Plotter. (D) DFS in Kaplan-Meier Plotter. (E) PFS in Kaplan-Meier Plotter. (F) DSS in Kaplan-Meier Plotter. OS, overall survival; DFS, disease free survival; PFS, progression free survival; DSS, disease specific survival; GEPIA, Gene Expression Profiling Interactive Analysis. 
A

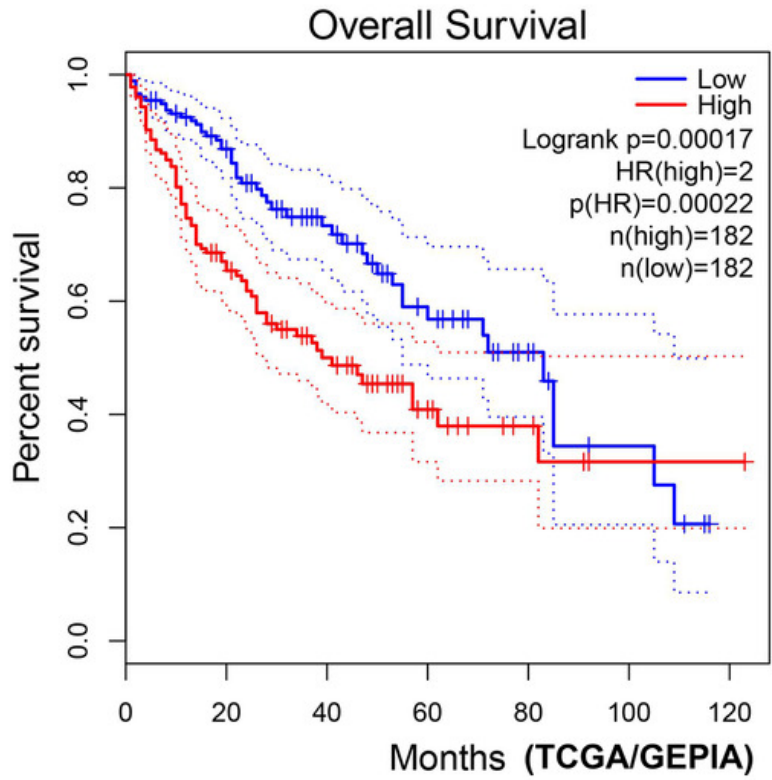

C

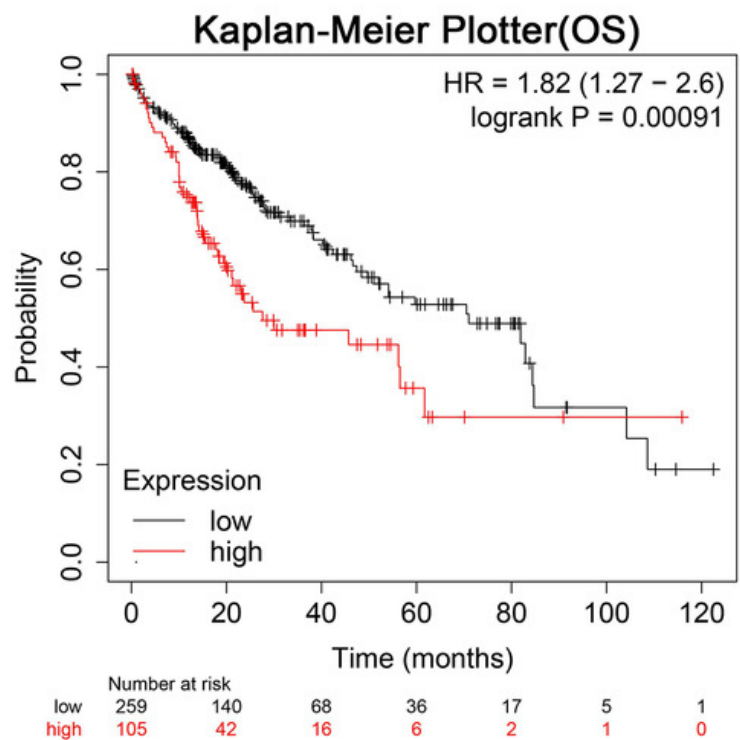

E

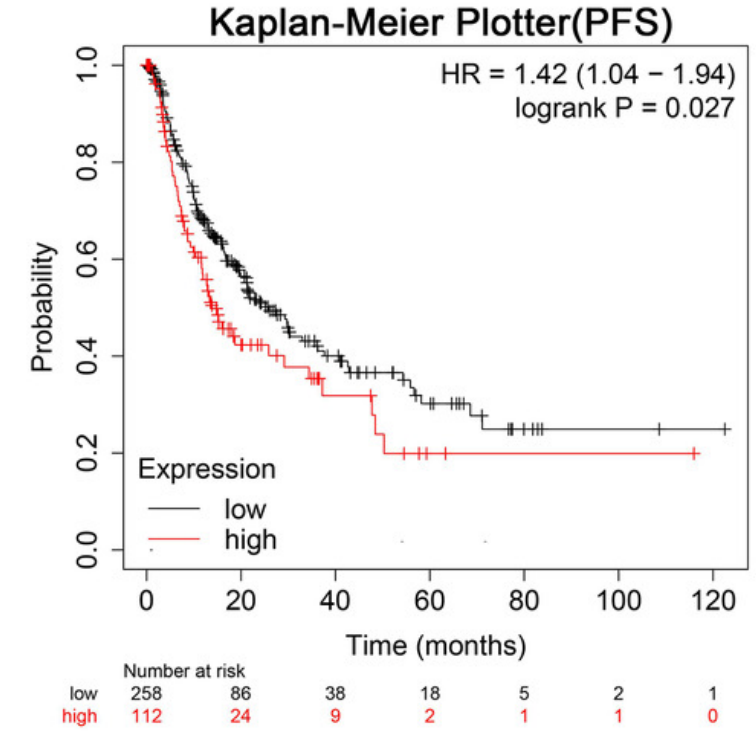

B

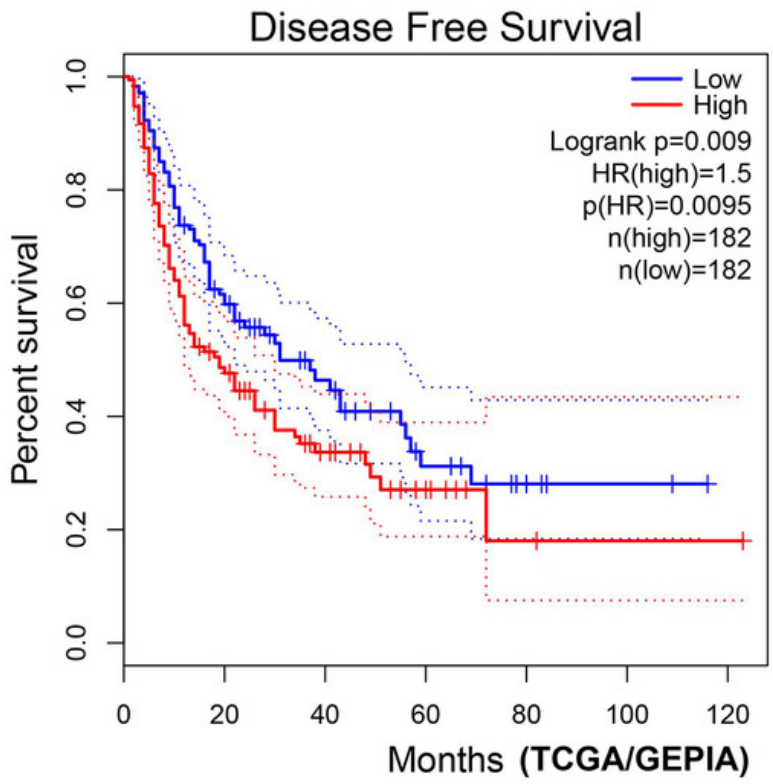

D

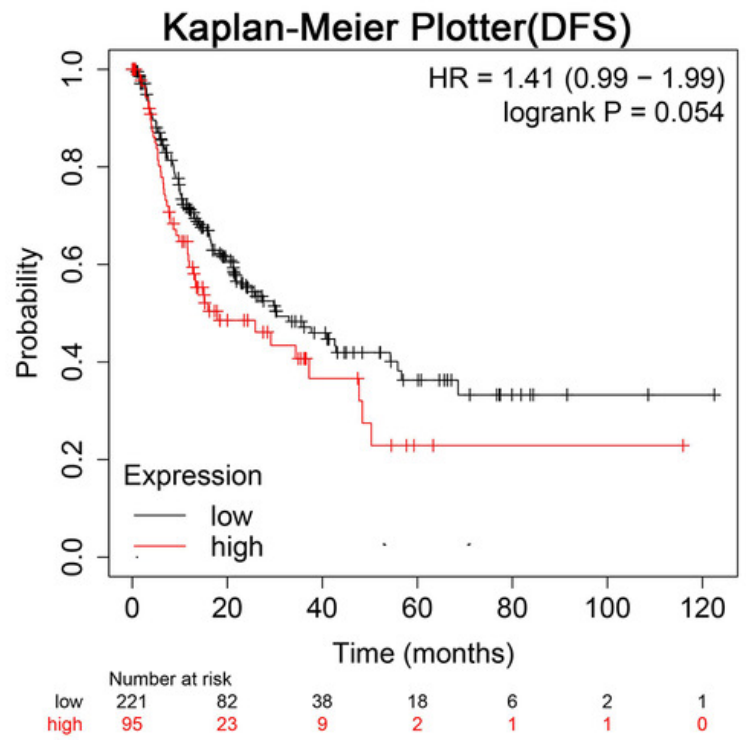

F

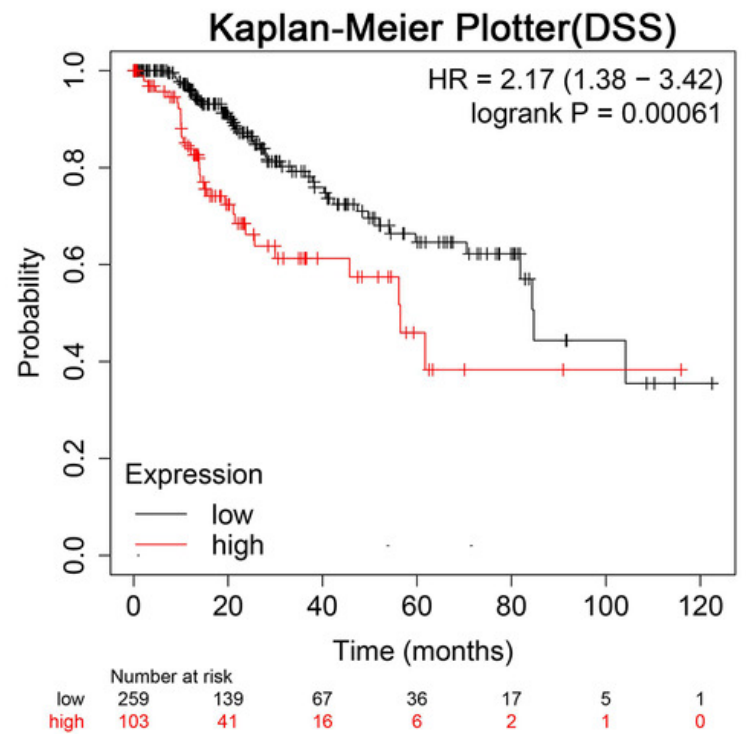


Figure 5

Analyses of mutant status of DUSP12 in HCC

Analyses of mutant status of DUSP12 in HCC. (A) Frequency of the DUSP12 mutation.

(B) Frequency of mutant types. (C) mRNA expression of DUSP12 in HCC cases with various

types of mutant status. (D) OS of DUSP12-altered and DUSP12-nonaltered groups. OS, overall survival.

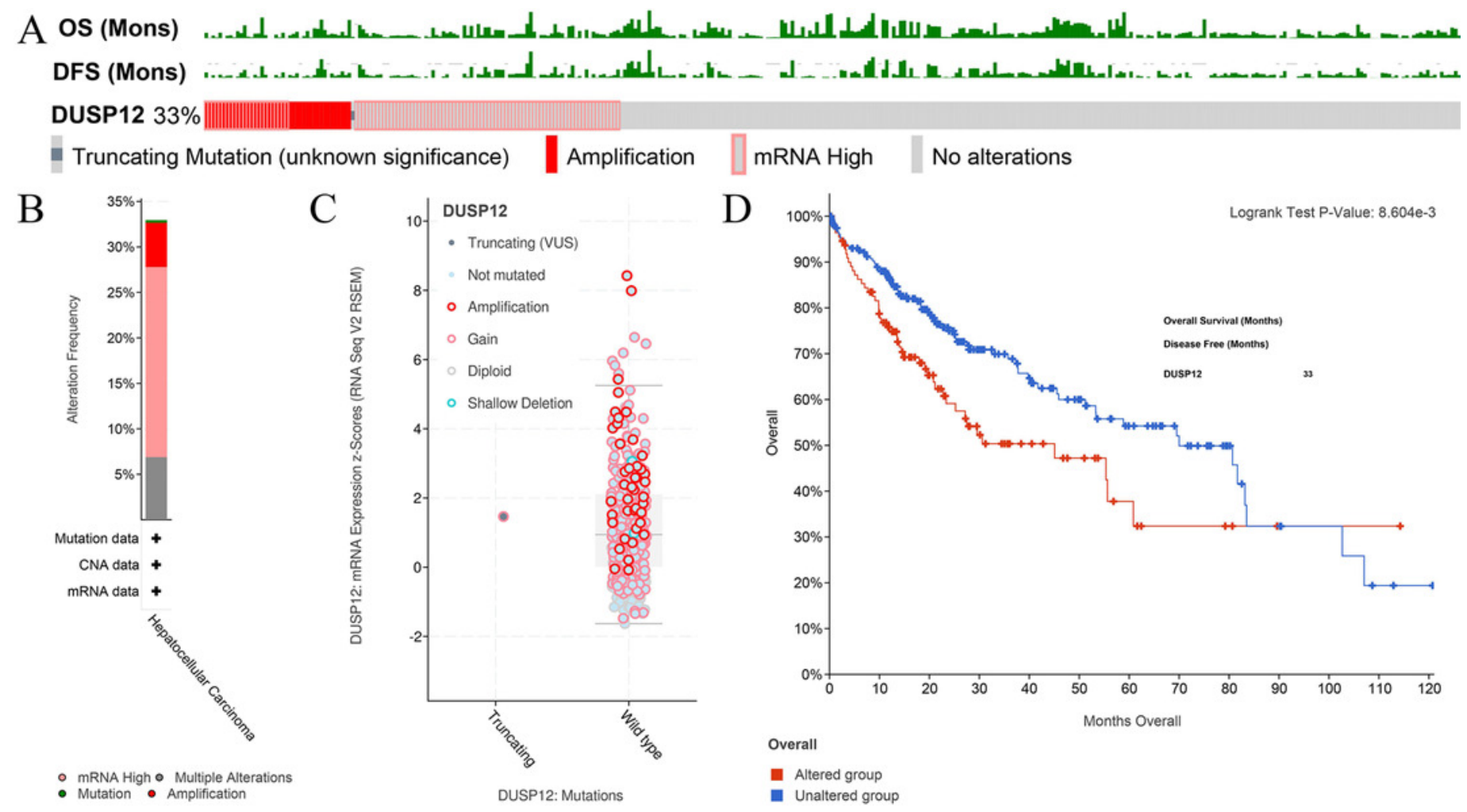




\section{Figure 6}

Clinical features of HCC patients with or without alteration of DUSP12 expression

Clinical features of HCC patients with or without alteration of DUSP12 expression.

(A) mRNA expression of DUSP12 in HCC patients with different copy numbers. (B)

Relationship between mRNA expression of DUSP12 and DUSP12 methylation. (C) AFP level at procurement in DUSP12-altered and DUSP12-nonaltered groups. (D) Fraction of genome altered in DUSP12-altered and DUSP12-nonaltered groups. (E) Histology grade in DUSP12altered and DUSP12-nonaltered groups. AFP, alpha-fetoprotein; $* P<0.05$, ***P $<0.001$. 


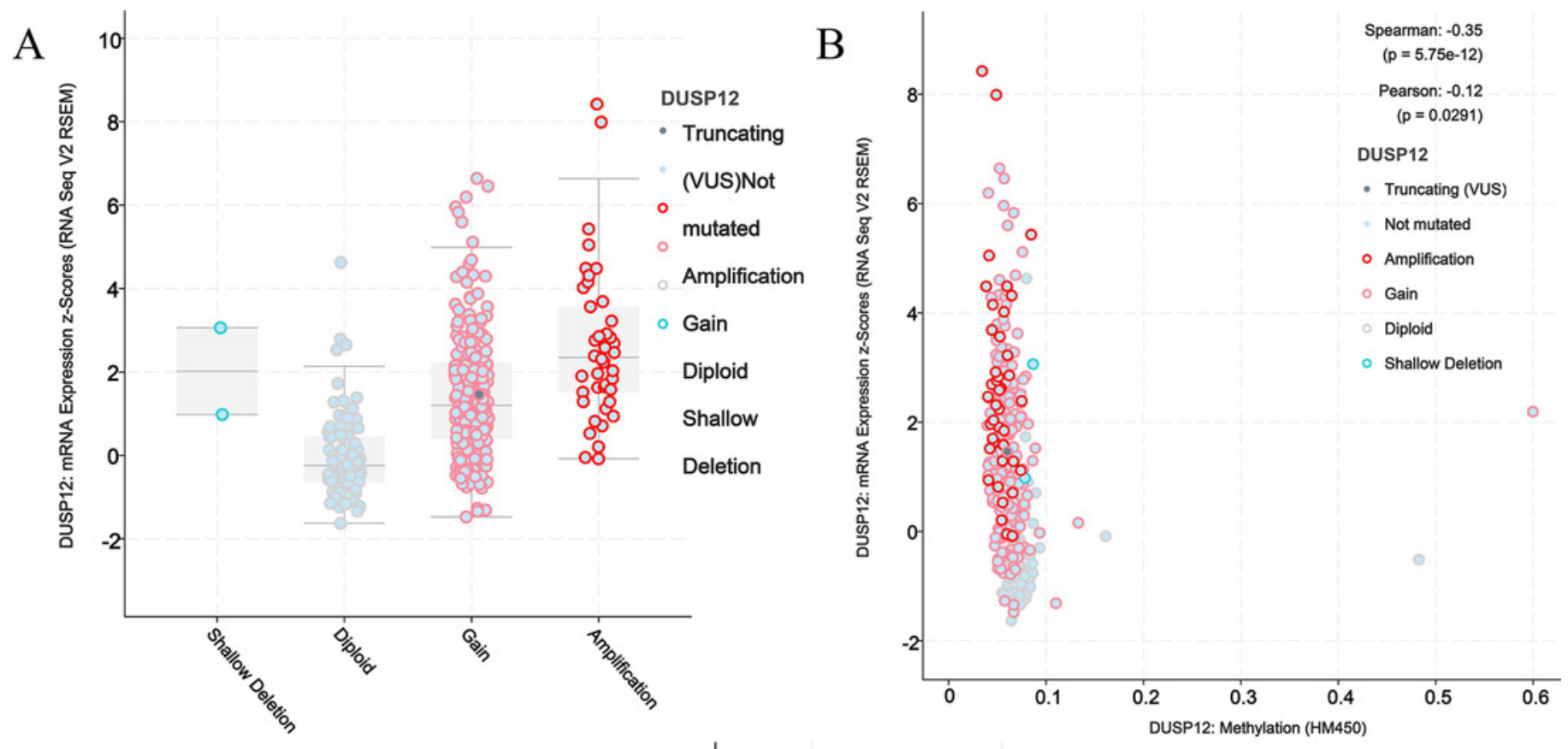

C

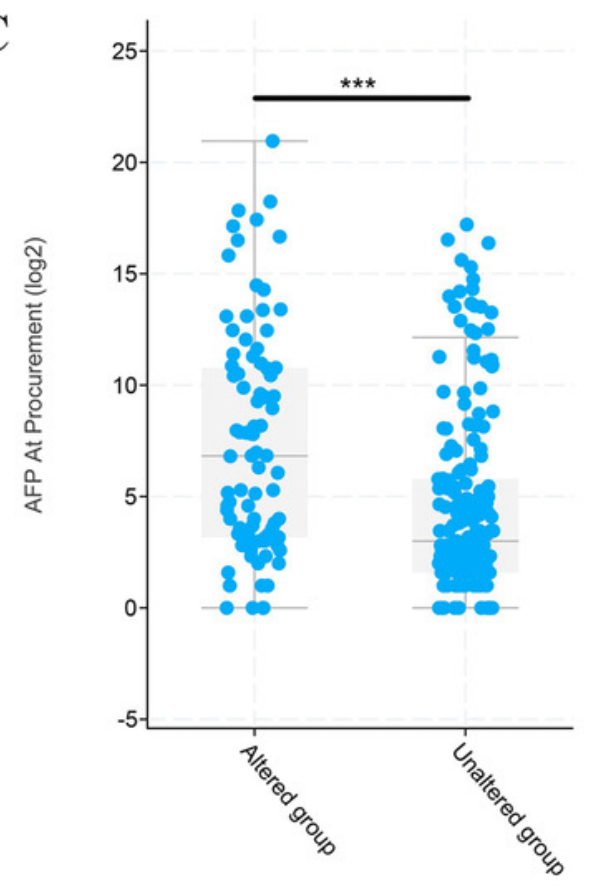

D

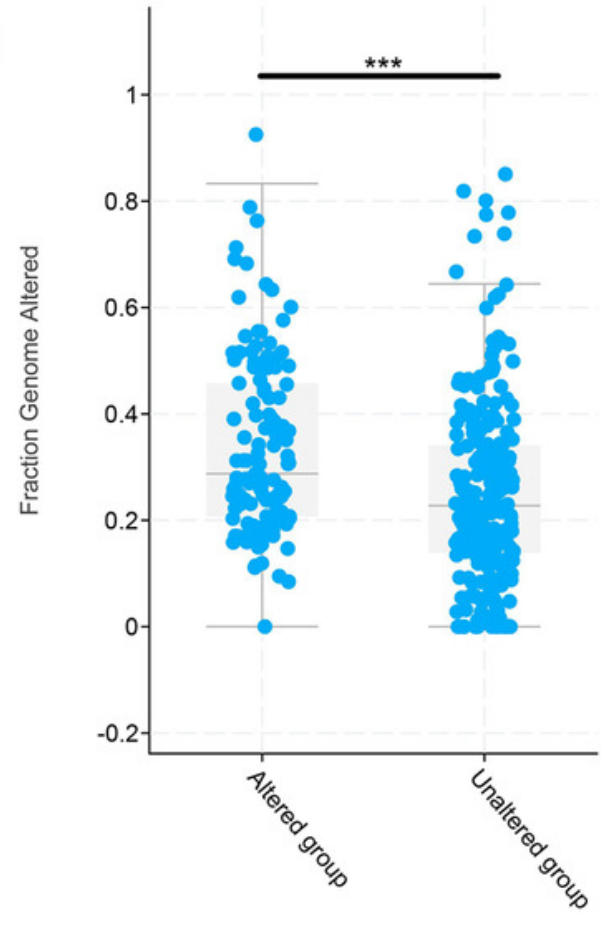

E

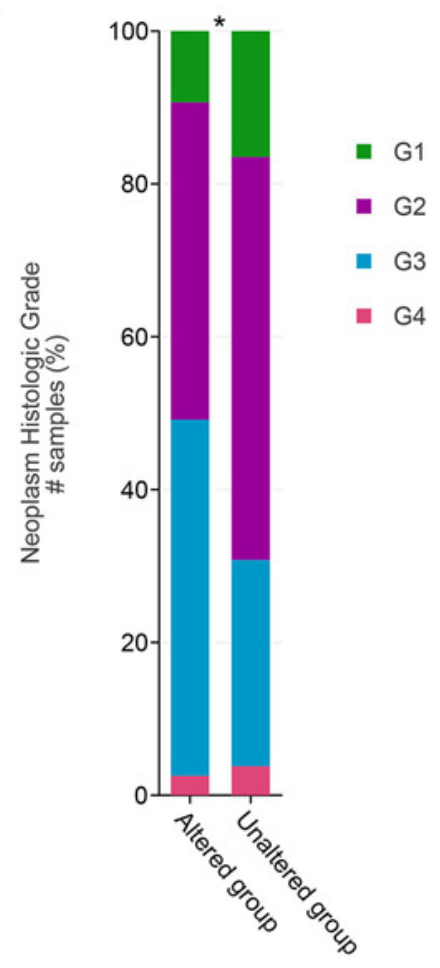


Figure 7

DEGs between HCC cases with altered and nonaltered DUSP12

DEGs between HCC cases with altered and nonaltered DUSP12. (A) Volcano plot of DEGs between HCC cases with altered and nonaltered DUSP12. (B) Heatmap for selected terms $(P<0.05)$. (C) Network colored by cluster. (D) MCODEs of the PPI network. DEGs, differentially expressed genes; MCODEs, Minimal Common Oncology Data Elements; PPI, protein-protein network.

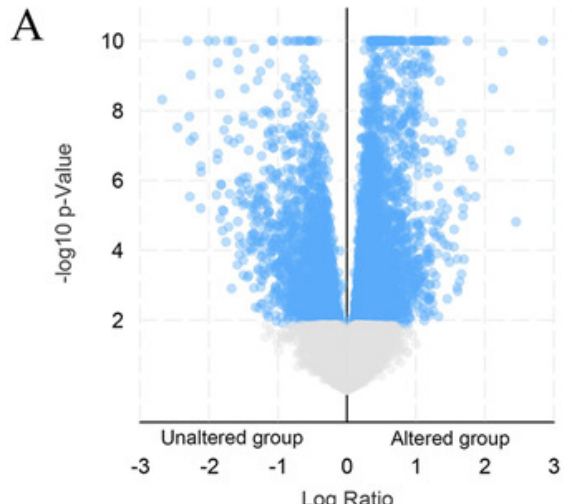

$\mathrm{C}$

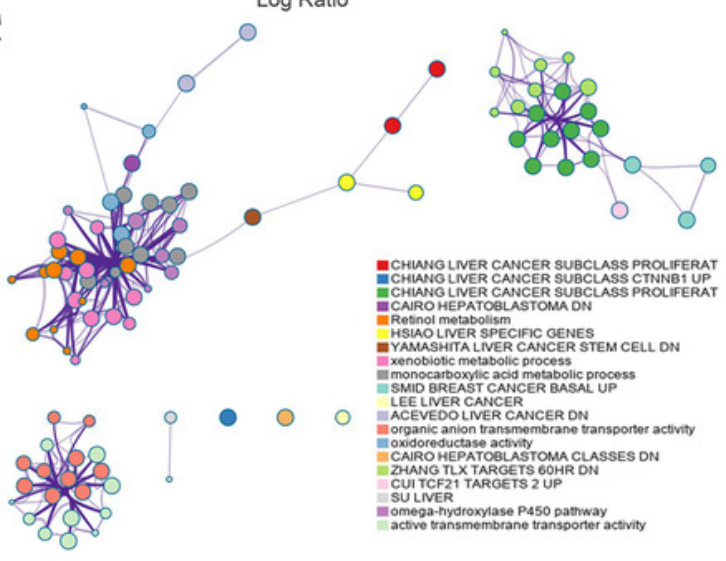

$\mathrm{B}$

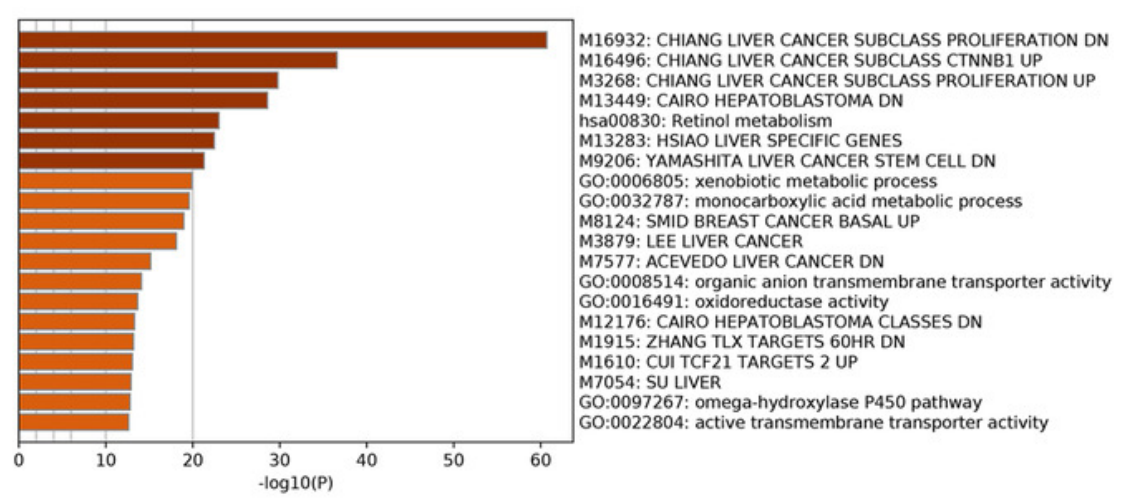

$\mathrm{D}$
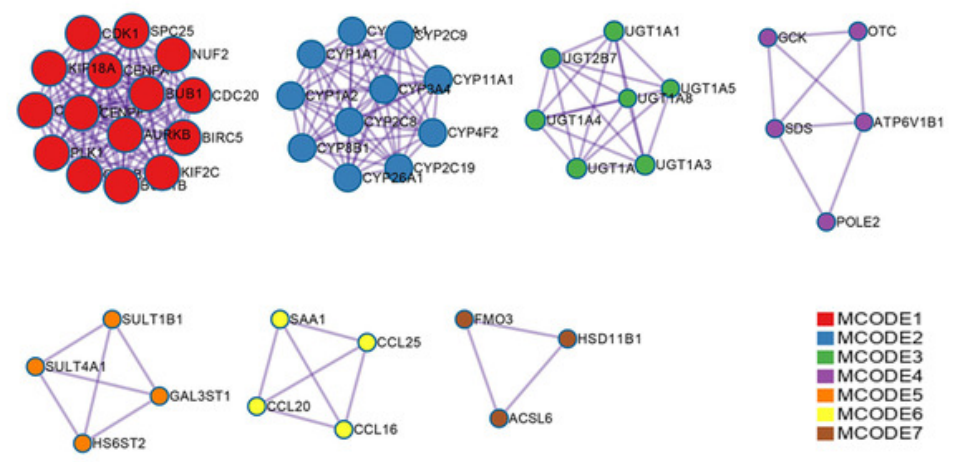


\section{Table $\mathbf{1}$ (on next page)}

The correaltion of DUSP12 and immune cell with 4 differernt immune-infiltration analyzing methods (adj.p $<0.05$ ).

The correaltion of DUSP12 and immune cell with 4 differernt immune-infiltration analyzing methods (adj.p < 0.05). 
1 Table 1. The correaltion of DUSP12 and immune cell with 4 differernt immune-infiltration 2 analyzing methods (adj.p < 0.05).

\begin{tabular}{|c|c|c|c|c|}
\hline Tools & infiltrates & rho & $\mathrm{p}$ & adj.p \\
\hline \multirow{14}{*}{$\mathrm{xCELL}$} & B cell memory_XCELL & $\begin{array}{l}0.14405756 \\
9\end{array}$ & 0.0073615 & $\begin{array}{l}0.04333762 \\
1\end{array}$ \\
\hline & \multirow{2}{*}{ B cell_XCELL } & 0.19943988 & \multicolumn{2}{|c|}{0.000192610 .00249504} \\
\hline & & 4 & 3 & 9 \\
\hline & \multirow{2}{*}{ Class-switched memory B cell_XCELL } & 0.18464639 & \multicolumn{2}{|c|}{0.000567070 .00570457} \\
\hline & & 1 & \multirow[t]{2}{*}{5} & \multirow[t]{2}{*}{6} \\
\hline & & - & & \\
\hline & Macrophage M2_XCELL & 0.51407595 & $1.15 \mathrm{E}-24$ & $3.30 \mathrm{E}-21$ \\
\hline & Macrophage_XCELL & $\begin{array}{l}- \\
0.24248663 \\
8\end{array}$ & $5.22 \mathrm{E}-06$ & $\begin{array}{l}0.00011508 \\
3\end{array}$ \\
\hline & $\begin{array}{l}\text { Myeloid_dendritic } \\
\text { activated_XCELL }\end{array}$ & $\begin{array}{l}0.19759636 \\
4\end{array}$ & 0.00022132 & $\begin{array}{l}0.00279187 \\
5\end{array}$ \\
\hline & Dlocmotrid dondritio 11 YCDI & & \multicolumn{2}{|c|}{0.005611020 .03606905} \\
\hline & Plasmacytord denaritic cen_XCELL & $\begin{array}{l}0.1488<3 / 1 \\
5\end{array}$ & 2 & 6 \\
\hline & T & 0.19644135 & \multicolumn{2}{|c|}{0.000241290 .00295357} \\
\hline & 1 cenco4t memory_גCELL & 1 & 3 & 4 \\
\hline & T cell CD4+ Th2_XCELL & $\begin{array}{l}0.36096079 \\
6\end{array}$ & $4.69 \mathrm{E}-12$ & $5.17 \mathrm{E}-10$ \\
\hline \multirow{4}{*}{ TIMER } & B cell_TIMER & $\begin{array}{l}0.41117329 \\
4\end{array}$ & $1.66 \mathrm{E}-15$ & $3.66 \mathrm{E}-13$ \\
\hline & Macrophage_TIMER & $\begin{array}{l}0.33798662 \\
8\end{array}$ & $1.15 \mathrm{E}-10$ & 8.78E-09 \\
\hline & Myeloid dendritic cell_TIMER & $\begin{array}{l}0.47671114 \\
3\end{array}$ & $5.62 \mathrm{E}-21$ & $4.03 \mathrm{E}-18$ \\
\hline & Neutrophil_TIMER & $\begin{array}{l}0.24622168 \\
9\end{array}$ & $3.69 \mathrm{E}-06$ & 8.33E-05 \\
\hline
\end{tabular}




\begin{tabular}{|c|c|c|c|c|}
\hline & T cell CD4+_TIMER & $\begin{array}{l}0.29848633 \\
9\end{array}$ & $1.57 \mathrm{E}-08$ & $6.73 \mathrm{E}-07$ \\
\hline \multirow{7}{*}{ EPIC } & \multirow{2}{*}{ B cell_EPIC } & 0.16273433 & \multicolumn{2}{|c|}{0.002430020 .01935243} \\
\hline & & 4 & 4 & 8 \\
\hline & & - & & \\
\hline & \multirow[t]{2}{*}{ Macrophage_EPIC } & 0.48098844 & $2.24 \mathrm{E}-21$ & \multirow[t]{2}{*}{$2.14 \mathrm{E}-18$} \\
\hline & & 6 & 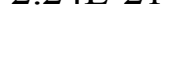 & \\
\hline & \multirow{2}{*}{$\mathrm{T}$ cell CD4+_EPIC } & 0.15194897 & \multicolumn{2}{|c|}{0.004676290 .03169486} \\
\hline & & 5 & 1 & 1 \\
\hline & B cell memory CIRER SORT_ARS & 0.14329214 & 0.0076841 & 10.04468631 \\
\hline & 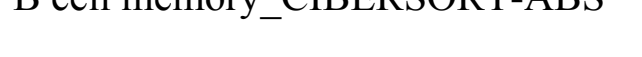 & 5 & 3 & 4 \\
\hline & $\mathrm{R}$ cell nlasm CIRER SORT $\triangle \mathrm{RS}$ & 0.15456266 & 0004005 & 0.02786974 \\
\hline & 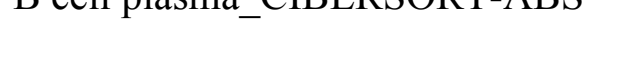 & 1 & 0.004000 & 8 \\
\hline & Macronhaoe M0 CIRERSORT & 0.18063036 & 0.0007499 & 0.00700321 \\
\hline & 年 & 9 & 9 & 8 \\
\hline & Macrophage M0 CIBERSORT-ABS & 0.30585966 & $6.63 \mathrm{E}-09$ & 3.22E-07 \\
\hline & 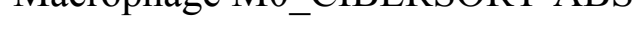 & 5 & & \\
\hline & Macrophage M1 CIBERSORT-ABS & 0.31494004 & $2.21 \mathrm{E}-09$ & 1.19E-07 \\
\hline CIBER & & 8 & 2. & 10 \\
\hline SORT & Macronhage M2 CIRERSORT_ARS & 0.34911549 & $252 \mathrm{~F}_{-1} 11$ & $226 \mathrm{~F}_{2} 09$ \\
\hline & VIACFOPHage IVIL_CIDEKSUKI-ADS & 4 & $2.02 \mathrm{~L}^{-11}$ & $2.20 \mathrm{E}-07$ \\
\hline & Myeloid dendritic & 10.17843401 & 0.0008716 & 10.00808709 \\
\hline & resting_CIBERSORT & 5 & 2 & 5 \\
\hline & $\begin{array}{lr}\text { Myeloid } & \text { dendritic } \\
\text { resting } & \text { CIBFRSORT-ABS }\end{array}$ & 0.21779062 & 4.51E-05 & 0.00073801 \\
\hline & $\mathrm{T} \quad$ cell $\quad \mathrm{CD} 4+$ & 0.26914539 & $388 F_{-} 07$ & 1 10F-05 \\
\hline & resting_CIBERSORT-ABS & 2 & & \\
\hline & T cell CD8+ CIBERSORT-ABS & 0.18680570 & 0.0004867 & 90.00505663 \\
\hline & לע & 3 & 1 & 2 \\
\hline
\end{tabular}


Figure 8

Correlation between DUSP12 expression and number of tumor-infiltrating immune cells

\section{Correlation between DUSP12 expression and number of tumor-infiltrating immune}

cells. (A) Pearson correlation between DUSP12 expression with TIICs abundance. (B) Pearson correlation between DUSP12 expression with immune-checkpoint moieties. (C) DUSP12 expression in HCC cases with different copy numbers. (D) DUSP12 expression in HCC cases with different immune subtypes. TIIC, tumor infiltrating immune cells. ${ }^{*} \mathrm{P}<0.05,{ }^{*} \mathrm{P}<0.01$.
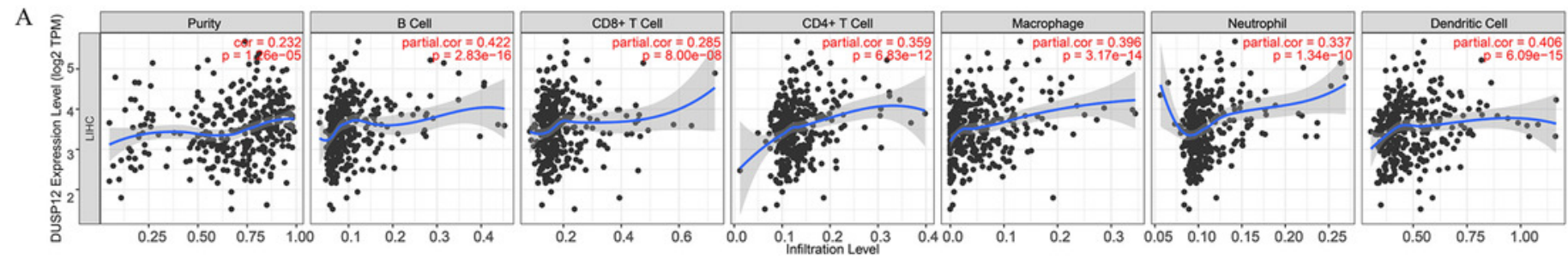

B
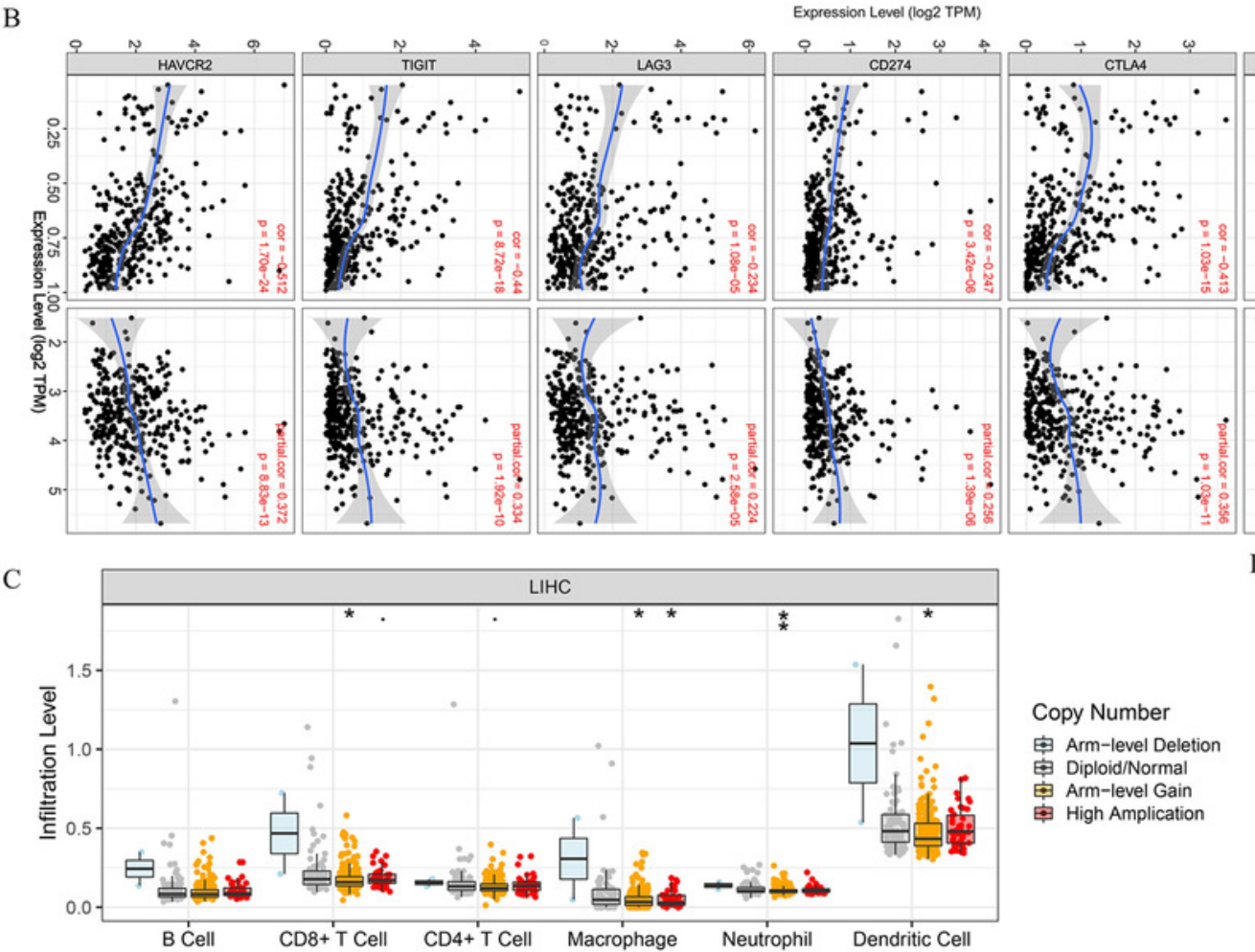

Copy Number

审 Arm-level Deletion

由 Diploid/Norma

审 Arm-level Gain

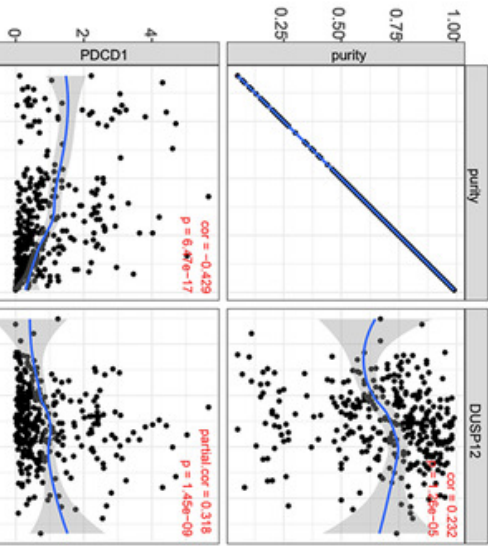

D

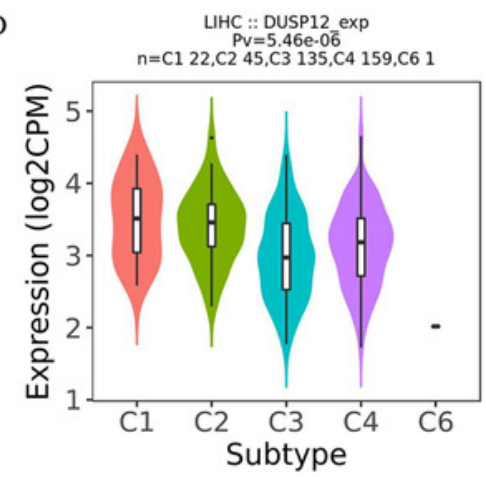


Figure 9

Ratio of various TIICs in HCC

Ratio of various TIICs in HCC. $* \mathrm{P}<0.05$. TIICs, tumor infiltrating immune cells.

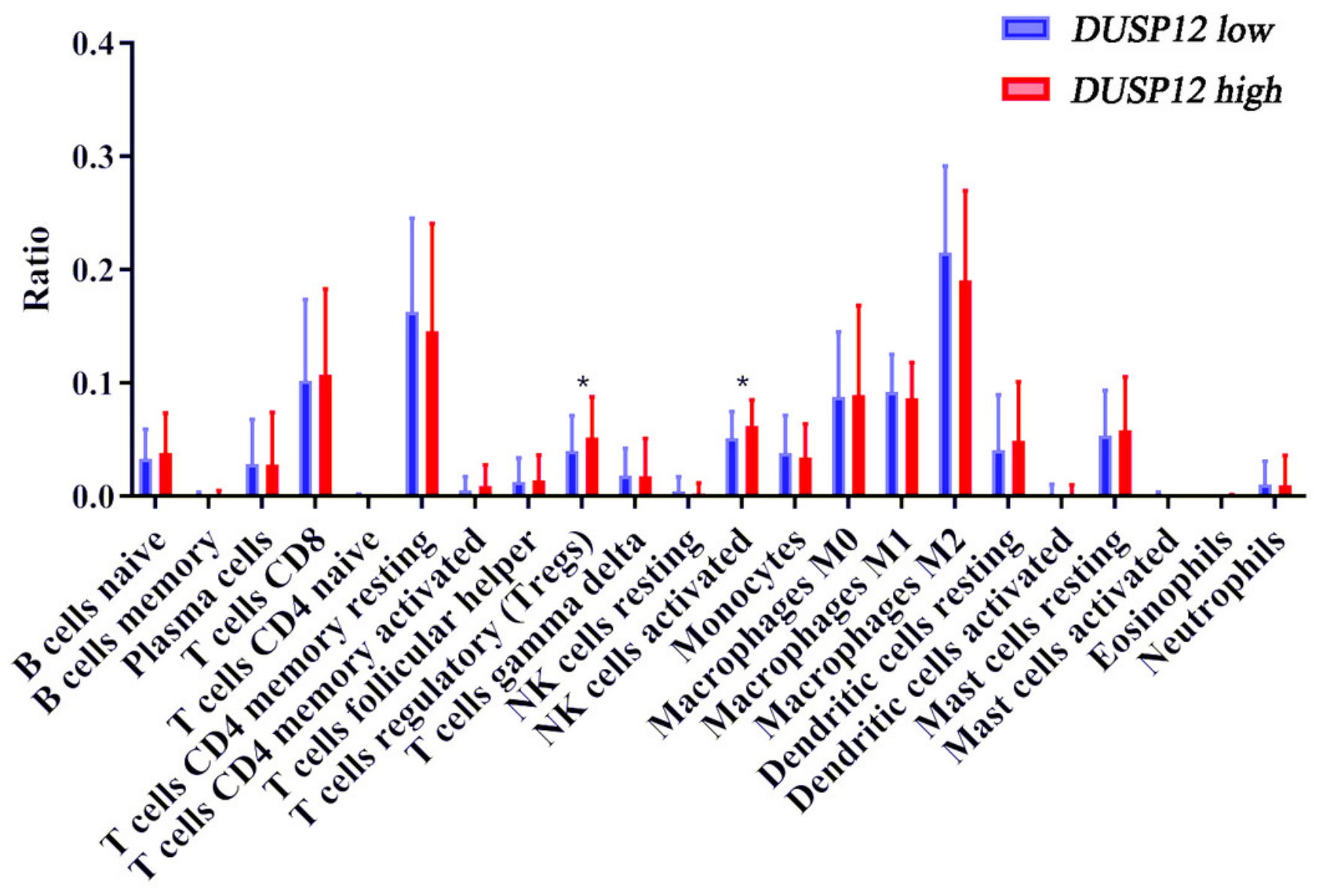


Figure 10

Knockdown of DUSP12 expression reduces the proliferation and migration of Huh7 cells

\section{Knockdown of DUSP12 expression reduces the proliferation and migration of Huh7}

cells. (A) Knockdown of DUSP12 expression in Huh7 cells. (B) Proliferation of cells according to the CCK8 assay. (C) Migration of cells according to the Transwell ${ }^{\mathrm{TM}}$ assay. ${ }^{* * * * P}<0.0001$.

A

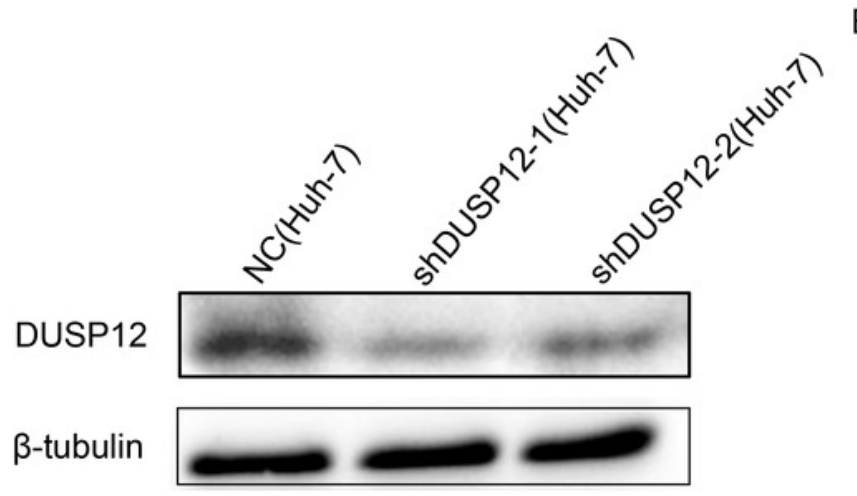

C

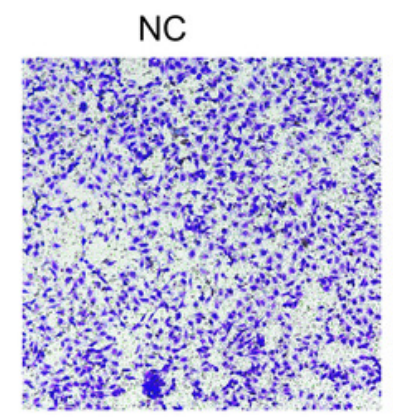

shDUSP12-1

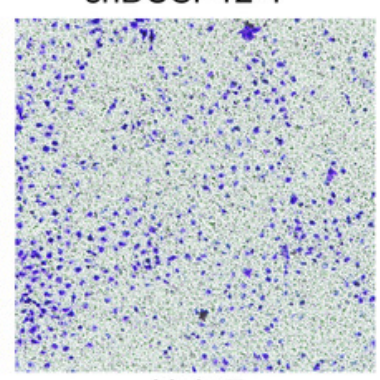

Huh-7
B

CCK8

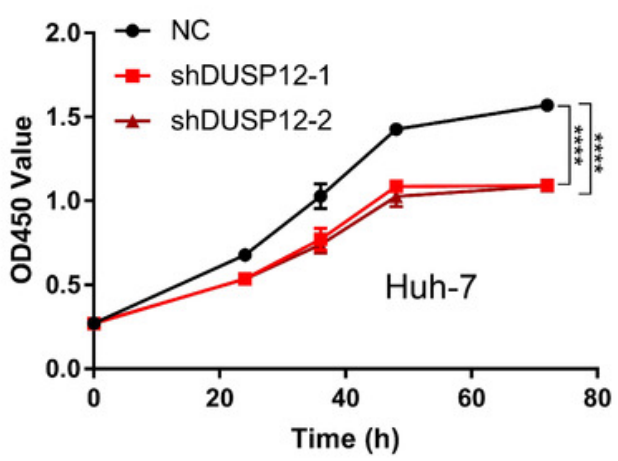

shDUSP12-2
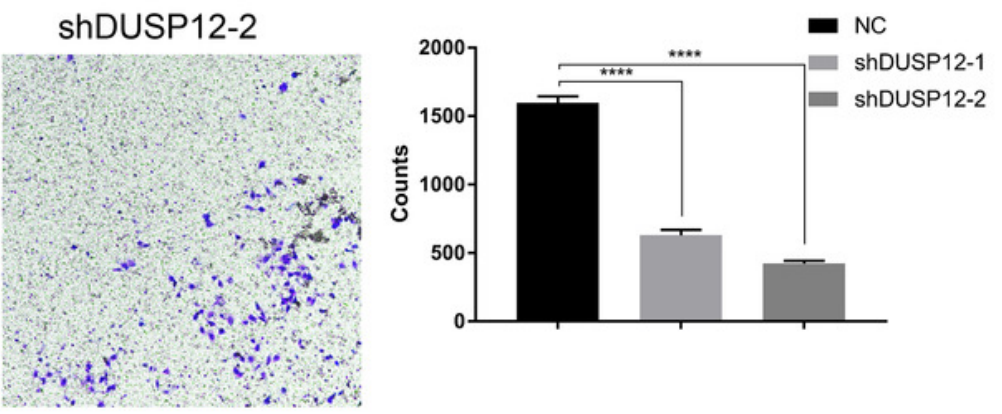